Gene expression profiling in patients with polymyalgia rheumatica before and after symptom-abolishing glucocorticoid treatment

Kreiner, Frederik Flindt; Borup, Rehannah; Nielsen, Finn Cilius; Schjerling, Peter; Galbo, Henrik

Published in:

BMC Musculoskeletal Disorders

DOI:

10.1186/s12891-017-1705-z

Publication date:

2017

Document version

Publisher's PDF, also known as Version of record

Document license:

CCO

Citation for published version (APA):

Kreiner, F. F., Borup, R., Nielsen, F. C., Schjerling, P., \& Galbo, H. (2017). Gene expression profiling in patients with polymyalgia rheumatica before and after symptom-abolishing glucocorticoid treatment. BMC

Musculoskeletal Disorders, 18, [341]. https://doi.org/10.1186/s12891-017-1705-z 


\title{
Gene expression profiling in patients with polymyalgia rheumatica before and after symptom-abolishing glucocorticoid treatment
}

Frederik Flindt Kreiner ${ }^{1}$, Rehannah Borup ${ }^{2}$, Finn Cilius Nielsen ${ }^{2}$, Peter Schjerling ${ }^{3}$ and Henrik Galbo ${ }^{1 *}$ (D)

\begin{abstract}
Background: The pathophysiology, including the impact of gene expression, of polymyalgia rheumatica (PMR) remains elusive. We profiled the gene expression in muscle tissue in PMR patients before and after glucocorticoid treatment.
\end{abstract}

Methods: Gene expression was measured using Affymetrix Human Genome U133 Plus 2.0 arrays in muscle biopsies from 8 glucocorticoid-naive patients with PMR and 10 controls before and after prednisolone-treatment for 14 days. For 14 genes, quantitative real-time PCR (qRT-PCR, $n=9$ in both groups) was used to validate the microarray findings and to further investigate the expression of genes of particular interest.

Results: Prednisolone normalized erythrocyte sedimentation rate (ESR) and C-reactive protein (CRP) in PMR patients. A total of 165 putatively clinically relevant, differentially expressed genes were identified (cut-off: fold difference $> \pm 1.2$, difference of mean $>30$, and $p<0.05$ ); of these, 78 genes differed between patients and controls before treatment, 131 genes responded to treatment in a given direction only in patients, and 44 fulfilled both these criteria. In 43 of the 44 genes, treatment counteracted the initial difference. Functional clustering identified themes of biological function, including regulation of protein biosynthesis, and regulation of transcription and of extracellular matrix processes. Overall, qRT-PCR confirmed the microarray findings: Microarray-detected group differences were confirmed for 9 genes in 17 of 18 comparisons (same magnitude and direction of change); lack of group differences in microarray testing was confirmed for 5 genes in 8 of 10 comparisons. Before treatment, using qRT-PCR, expression of interleukin 6 (IL-6) was found to be 4 -fold higher in patients $(p<0.05)$.

Conclusions: This study identifies genes in muscle, the expression of which may impact the pathophysiology of PMR. Moreover, the study adds further evidence of the importance of IL-6 in the disease. Follow-up studies are needed to establish the exact pathophysiological relevance of the identified genes.

The study was retrospectively listed on the ISRCTN registry with study ID ISRCTN69503018 and date of registration the 26th of July 2017.

Keywords: Polymyalgia rheumatica, DNA microarray, Muscle, Gene expression, Prednisolone, Interleukin 6

\footnotetext{
*Correspondence: hga@sund.ku.dk

${ }^{1}$ Institute for Inflammation Research, Department of Rheumatology

Rigshospitalet, Copenhagen University Hospital, Copenhagen, Denmark

Full list of author information is available at the end of the article
}

(c) The Author(s). 2017 Open Access This article is distributed under the terms of the Creative Commons Attribution 4.0 International License (http://creativecommons.org/licenses/by/4.0/), which permits unrestricted use, distribution, and reproduction in any medium, provided you give appropriate credit to the original author(s) and the source, provide a link to the Creative Commons license, and indicate if changes were made. The Creative Commons Public Domain Dedication waiver (http://creativecommons.org/publicdomain/zero/1.0/) applies to the data made available in this article, unless otherwise stated. 


\section{Background}

Polymyalgia rheumatica (PMR) affects men and women above the age of 50 and is recognized as the most common chronic inflammatory, rheumatic disease in this age group [1-3]. Clinically, PMR is associated with prominent muscle complaints, including aching and tender and stiff proximal muscles [1]. Paraclinically, erythrocyte sedimentation rate (ESR) and blood levels of C-reactive protein (CRP) are markedly elevated [1]. Furthermore, concentrations of proinflammatory cytokines, including also interleukin (IL) 6 [4, 5], are elevated systemically as well as locally in muscle tissue [5]. Yet, the prevailing view is that PMR reflects inflammation in the synovia of bursae, joints and tendon sheaths [6]. Overall, however, the current understanding of the etiology, pathogenesis and pathophysiology of PMR is modest. Treatment with glucocorticoids (GCs) is rapidly effective $[7,8]$, and the majority of patients maintains remission, but many experience at least one GCrelated serious adverse event [9].

The genetics of PMR remain elusive; however, the higher incidence in Caucasians [10] and the higher susceptibility in people carrying the HLA-DRB1*04 allele [11] suggest that genetic factors may in fact impact the pathophysiology of the disease. Studies have found associations between polymorphisms in the genes encoding e.g. IL-6 and tumor necrosis factor alpha (TNF- $\boldsymbol{\alpha}$ ) and the susceptibility to and severity of PMR [12], but generally findings have been inconclusive $[13,14]$.

In the present study, to extend the understanding of the pathophysiology of PMR, we profiled the gene expression in muscle tissue from GC-naive patients with PMR and matched non-PMR control subjects before and after symptom-eliminating treatment with prednisolone.

\section{Methods}

\section{Subjects}

Nine GC-naive patients with newly diagnosed, untreated PMR and 10 matched (age, sex, and BMI) non-PMR control subjects were studied in the fasting state in the morning before and after 14 days of prednisolone treatment $(20 \mathrm{mg} /$ day taken in the morning, also $1-2 \mathrm{~h}$ before the second biopsy) in a comprehensive clinical experimental research program, some of the results of which we recently reported $[5,15]$. The study was approved by the Ethical Committee of Copenhagen (approval number: KF[01]261665) and informed consent was obtained before study inclusion. Anthropometric data are given in Table 1.

Patients were diagnosed with PMR according to the criteria proposed by Chuang and colleagues [2, 3, 16, 17], and the diagnosis was later supported by normalization of ESR and CRP upon prednisolone treatment. Patients were recruited by referral from general practitioners; control subjects were recruited by newspaper advertising and included
Table 1 Characteristics of the PMR patients and the non-PMR control subjects

\begin{tabular}{|c|c|c|}
\hline & $\begin{array}{l}\text { PMR patients } \\
(n=9)\end{array}$ & $\begin{array}{l}\text { Controls } \\
(n=10)\end{array}$ \\
\hline Female/male & $5 / 4$ & $5 / 5$ \\
\hline Age, mean (range), years & $74.2(60.5-87.2)$ & $72.3(63.4-85.2)$ \\
\hline $\begin{array}{l}\text { Body-mass index, mean (range), } \\
\mathrm{kg} / \mathrm{m}^{2}\end{array}$ & $24.3(16.5-28.7)$ & $25.7(22.1-29.3)$ \\
\hline \multicolumn{3}{|l|}{ ESR, mean (range) mm/h } \\
\hline Before treatment & $66(43-74)^{\dagger}$ & $9(3-11)$ \\
\hline After treatment & $13(4-23)^{\ddagger}$ & $7(4-10)$ \\
\hline \multicolumn{3}{|l|}{ CRP, mean (range) mg/l } \\
\hline Before treatment & $55(27-131)^{\dagger}$ & $2(0-10)$ \\
\hline After treatment & $5(0-11)^{\ddagger}$ & $2(1-8)$ \\
\hline
\end{tabular}

${ }^{\dagger} p<0.05$ vs. control subjects. ${ }^{\ddagger} p<0.05$ vs. untreated patients

in the study after a standard medical examination and a comprehensive blood and urine screening. Both groups did not meet the exclusion criteria described by Kreiner and colleagues [5]. Controlled chronic comorbidities were accepted in both groups. Diminishing the possibility of occult malignant disease, all subjects had normal thorax X-ray and abdominal ultrasound examination, and negative test for blood in the stools and urine. In addition, all subjects had comprehensive blood screening performed. In patients, only ESR and CRP were different from normal values; no blood values in control subjects were abnormal.

Some subjects received concurrent medication as previously detailed [5]. Before the first experiment, nonsteroidal anti-inflammatory drug treatment was not allowed, and use of analgesics was limited to the centrally-acting opioid-like drug tramadol (Mandolgin, Mandoz A/S, Odense, Denmark); none of the subjects had taken tramadol in the morning before any of the two experiments.

\section{Experiments and interventions}

From all subjects, biopsies were obtained from trapezius muscles before and after treatment with prednisolone; in all patients, the trapezius muscle exhibited the symptoms characteristic of PMR, i.e. aching, tenderness and stiffness. Following local anesthesia of the skin and subcutis with Lidocaine $(20 \mathrm{mg} / \mathrm{mL})$, muscle tissue was sampled through a small incision in the cutis, subcutis and muscle fascia using a $5 \mathrm{~mm}$ Bergström needle with suction [18]. Muscle samples were snap-frozen in liquid nitrogen, weighed (wet weight ranged from 35 to $100 \mathrm{mg}$ per sample), and stored at $-80{ }^{\circ} \mathrm{C}$ until RNA extraction.

\section{Total RNA extraction}

Total RNA was extracted from 20 to $30 \mathrm{mg}$ muscle sample by tissue homogenization in TriReagent (Molecular 
Research Center, Cincinnati, Ohio, US) using a beadmixer (FastPrep ${ }^{\oplus}-24$ instrument, MP Biomedicals, Illkirch, France) with five inert $2.3 \mathrm{~mm}$ steel beads (BioSpec Products, Bartlesville, OK, US) and one siliciumcarbid crystal followed by addition of bromo-chloropropane to separate the homogenate into aqueous and organic phases. To precipitate RNA, isopropanol was added to the isolated aqueous phase. The precipitated total RNA was washed repeatedly in $75 \%$ ethanol and dissolved in RNAse-free water before storing at $-80{ }^{\circ} \mathrm{C}$ until further analysis. Total RNA concentrations were determined by spectroscopy; yields averaged $0.4 \mu \mathrm{g}$ total RNA/mg muscle tissue.

\section{DNA microarray analysis}

\section{Sample preparation and hybridization, and detection and} quantification of signals

Total RNA was further purified using RNeasy Mini Kits (Qiagen, Valencia, CA, US), and the integrity and purity of the RNA was verified using an Agilent Bioanalyser (Agilent, Palo Alto, CA, US) as previously described [19]. Based on the quality of the RNA, 8 patient samples and 10 control subject samples were selected for microarray assessment. ds-cDNA was synthesized from $2 \mu \mathrm{g}$ total RNA using an oligo-dT primer containing a T7 RNA polymerase promoter, and labeled in an T7 promoterdriven in vitro transcription reaction producing biotinlabeled cRNA from the cDNA according to the manufacturer's (Affymetrix, Santa Clara, CA, US) guidelines. Next, the hybridization mixture was prepared from the fragmented target cRNA as well as probe array controls, bovine serum albumin, and herring sperm DNA.

Affymetrix GeneChip Human Genome U133 Plus 2.0 (Santa Clara, CA, US) arrays, which comprise 54,675 probe sets, were used. Following hybridization, the probe arrays were washed and stained with phycoerytrin streptavidin (SAPE) using the Affymetrix Fluidics Station 450 and scanned using an Affymetrix GeneArray 3000 7G scanner $488 \mathrm{~nm}$ to generate fluoresecent images as described in the Affymetrix GeneChip protocol. The amount of bound target at each location of the probe array is proportional to the amount of bound light emitted at $570 \mathrm{~nm}$. Scanned data were stored as image files in cel-format.

\section{Data analysis}

Cel-files were imported into the statistical software package R v. 2.7.2 using BioConductor v. 2.8 [20], and gcRMA modeled using quantiles normalization and median polish summarization [21]. The modeled log-intensity of approximately 54,600 probe sets was used for selecting differentially expressed genes. The microarray data were submitted to the gene expression repository at Array Express (http://www.ebi.ac.uk/arrayexpress/) with accession number E-MTAB-3671. Differentially expressed genes were selected based on an initial two-way ANOVA analysis including the parameters disease (PMR versus control) and treatment (before versus after treatment) with a $p$-value $<0.05$ and mutual fold change cut-off of 1.2 and reflecting either main effect or intervention. The resulting 565 selected probe sets were further analyzed. Pairwise differentially expressed transcripts were depicted by a univariate two-sample t-test with equal variance. Multiple testing corrections were performed using the multtest package in Bioconducter v. 2.7.2. Control of Type I error rate was performed by computing adjusted $p$-values for simple multiple testing procedures from a vector of raw (unadjusted) $p$-values by applying the Benjamini \& Hochberg FDR analysis [22]. Only transcripts exhibiting a fold change larger than 1.2 and a difference of means larger than 30 (real unlogged values) between (mutual) classes were considered.

\section{Gene grouping criteria}

Predefined criteria were applied to identify genes of potential pathophysiological impact. The criteria were: 1 . difference in expression level between untreated patients and untreated controls (Table 2), and 2. response to prednisolone treatment of expression levels in a given direction in patients only (Table 3). Those genes that differed between untreated patients and controls and that also responded to prednisolone treatment in patients, i.e. the aggregate of criteria 1 and 2, were also identified (criterion 3) (Table 4).

\section{Assessment of biological function}

For genes in all three criteria sets, biological functions were assessed using the Database for Annotation, Visualization and Integrated Discovery (DAVID) tool [23] with default options and annotations current as of February 2013. Functional annotation clustering was performed; this process associates individual genes in a large gene list with biological terms and group sets of genes according to functionally similar terms. Moreover, the importance of each cluster is ranked using enrichment scores, which are the geometric means of the enrichment $P$ values (EASE score [24]) for each annotation term in the cluster. While enrichment scores above 1.3 are considered particularly interesting, clusters with scores below 1.3 could also be of central importance (e.g. short gene lists do not generally get very high enrichment scores, illustrating that categories with lower scores may still be biologically relevant) [23]. In the presentation of the results, clusters with the highest enrichment scores will be presented.

\section{Quantitative RT-PCR}

To confirm mRNA level fold differences and fold changes found using the microarrays, mRNA levels for a selection (Tables 5 and 6) of the filtered genes were 
Table 2 Genes the expression levels of which differed between untreated patients and untreated controls (78 genes)

\begin{tabular}{|c|c|c|c|c|}
\hline Gene symbol & Gene name & Probe set(s) & $\mathrm{FD}^{\mathrm{a}}$ & $\mathrm{p}$ \\
\hline BDNF & brain-derived neurotrophic factor & 244503_at & +1.8 & 0.016 \\
\hline ETS2 & v-ets erythroblastosis virus E26 oncogene homolog 2 (avian) & 201328_at & +1.8 & 0.007 \\
\hline SVIP & small VCP/p97-interacting protein & 230285_at & +1.7 & 0.002 \\
\hline SH3RF2 & $\mathrm{SH} 3$ domain containing ring finger 2 & 228892_at & +1.6 & 0.004 \\
\hline TM4SF18 & transmembrane $4 \mathrm{~L}$ six family member 18 & 230061_at & +1.5 & 0.007 \\
\hline TMTC1 & transmembrane and tetratricopeptide repeat containing 1 & $\begin{array}{l}\text { 226322_at } \\
\text { 226931_at }\end{array}$ & $\begin{array}{l}+1.5 \\
+1.6\end{array}$ & $\begin{array}{l}0.003 \\
<0.001\end{array}$ \\
\hline TMEM18 & transmembrane protein 18 & 225489_at & +1.5 & 0.008 \\
\hline N4BP2L1 & NEDD4 binding protein 2-like 1 & 213375_s_at & +1.5 & 0.019 \\
\hline FMO2 & flavin containing monooxygenase 2 (non-functional) & 228268_at & +1.5 & 0.002 \\
\hline RPL37 & ribosomal protein $L 37$ & 224763_at & +1.5 & $<0.001$ \\
\hline CTDSP2 & $\begin{array}{l}\text { CTD (carboxy-terminal domain. RNA polymerase II. polypeptide A) } \\
\text { small phosphatase } 2\end{array}$ & 238999_at & +1.4 & 0.048 \\
\hline RASL10B & RAS-like. Family 10. member B & 235488_at & +1.4 & 0.012 \\
\hline SMG1P1 & nuclear pore complex interacting protein-like & 231989_s_at & +1.4 & 0.008 \\
\hline ZNF331 & zinc finger protein 331 & 219228_at & +1.4 & $<0.001$ \\
\hline FAM184B & family with sequence similarity 184 . member B & 235288_at & +1.4 & 0.013 \\
\hline LOC100507303 & uncharacterized LOC100507303 & 228049_x_at & +1.4 & 0.019 \\
\hline NCKIPSD & NCK interacting protein with $\mathrm{SH} 3$ domain & 218697_at & +1.4 & $<0.001$ \\
\hline ECHDC3 & enoyl CoA hydratase domain containing 3 & 219298_at & +1.3 & 0.049 \\
\hline RNF114 & ring finger protein 114 & $\begin{array}{l}\text { 200867_at } \\
\text { 200868_s_at } \\
211678 \text { _sat }\end{array}$ & $\begin{array}{l}+1.3 \\
+1.3 \\
+1.2\end{array}$ & $\begin{array}{l}0.006 \\
0.023 \\
0.018\end{array}$ \\
\hline TMPO & thymopoietin & 224944_at & +1.3 & 0.002 \\
\hline RERE & arginine-glutamic acid dipeptide (RE) repeats & 200940_s_at & +1.3 & 0.003 \\
\hline TUBD1 & tubulin. Delta 1 & 231853_at & +1.3 & 0.003 \\
\hline MARK4 & MAP/microtubule affinity-regulating kinase 4 & 55065_at & +1.3 & 0.005 \\
\hline ZNF195 & zinc finger protein 195 & 204234_s_at & +1.3 & 0.003 \\
\hline PCF11 & $\begin{array}{l}\text { PCF11. cleavage and polyadenylation factor subunit. Homolog } \\
\text { (S. cerevisiae) }\end{array}$ & 203378_at & +1.3 & 0.007 \\
\hline DFFA & DNA fragmentation factor. $45 \mathrm{kDa}$. alpha polypeptide & 226116_at & +1.3 & 0.010 \\
\hline PSPC1 & paraspeckle component 1 & 218371_s_at & +1.3 & 0.007 \\
\hline RBBP6 & retinoblastoma binding protein 6 & 212783_at & +1.3 & 0.004 \\
\hline EIF4B & eukaryotic translation initiation factor $4 \mathrm{~B}$ & 211937_at & +1.3 & 0.017 \\
\hline NPM1 & nucleophosmin (nucleolar phosphoprotein B23. numatrin) & 221691_x_at & +1.3 & 0.011 \\
\hline RSBN1 & round spermatid basic protein 1 & 213694_at & +1.2 & 0.003 \\
\hline PSIP1 & PC4 and SFRS1 interacting protein 1 & 209337_at & +1.2 & 0.010 \\
\hline EIF3G & eukaryotic translation initiation factor 3. subunit $\mathrm{G}$ & 208887_at & +1.2 & 0.006 \\
\hline COL4A3BP & collagen. Type IV. alpha 3 (Goodpasture antigen) binding protein & $\begin{array}{l}\text { 219625_s_at } \\
\text { 223465_at }\end{array}$ & $\begin{array}{l}+1.2 \\
+1.2\end{array}$ & $\begin{array}{l}0.003 \\
0.029\end{array}$ \\
\hline PCID2 & $\mathrm{PCl}$ domain containing 2 & 219940_s_at & +1.2 & 0.003 \\
\hline PXDC1 & PX domain containing 1 & 212923_s_at & +1.2 & 0.042 \\
\hline $\mathrm{BCKDHA}$ & branched chain keto acid dehydrogenase E1, alpha polypeptide & 202331_at & +1.2 & 0.024 \\
\hline AKR7A2 & aldo-keto reductase family 7 , member $\mathrm{A} 2$ & 202139_at & +1.2 & 0.010 \\
\hline MRPS2 & mitochondrial ribosomal protein S2 & 218001_at & +1.2 & 0.018 \\
\hline RORA & RAR-related orphan receptor A & 226682_at & +1.2 & 0.049 \\
\hline
\end{tabular}


Table 2 Genes the expression levels of which differed between untreated patients and untreated controls (78 genes) (Continued)

\begin{tabular}{|c|c|c|c|c|}
\hline RPL36AL & ribosomal protein L36a-like & 207585_s_at & +1.2 & 0.011 \\
\hline TFRC & transferrin receptor (p90, CD71) & 208691_at & -3.0 & 0.004 \\
\hline SFRP4 & secreted frizzled-related protein 4 & $\begin{array}{l}\text { 204051_s_at } \\
\text { 204052_s_at }\end{array}$ & -2.9 & 0.001 \\
\hline NOV & nephroblastoma overexpressed & 214321_at & -2.0 & 0.037 \\
\hline PAQR9 & progestin and adipoQ receptor family member IX & 1558322_a_at & -2.0 & $<0.001$ \\
\hline C2orf88 & chromosome 2 open reading frame 88 & 228195_at & -1.9 & 0.011 \\
\hline FAM69A & family with sequence similarity 69 , member $A$ & 213689_x_at & -1.8 & 0.001 \\
\hline TP53INP2 & tumor protein p53 inducible nuclear protein 2 & 224836_at & $\begin{array}{l}-1.8 \\
-1.9\end{array}$ & $\begin{array}{l}<0.001 \\
0.002\end{array}$ \\
\hline SH3KBP1 & SH3-domain kinase binding protein 1 & $\begin{array}{l}\text { 1554168_a_at } \\
\text { 223082_at }\end{array}$ & -1.8 & 0.002 \\
\hline NINJ2 & ninjurin 2 & 219594_at & -1.7 & 0.039 \\
\hline MEST & mesoderm specific transcript homolog (mouse) & 202016_at & -1.7 & 0.010 \\
\hline ITGB1BP2 & integrin beta 1 binding protein (melusin) 2 & 219829_at & -1.6 & $<0.001$ \\
\hline PLXDC1 & plexin domain containing 1 & 219700_at & -1.5 & 0.006 \\
\hline BPGM & 2,3-bisphosphoglycerate mutase & 203502_at & -1.5 & $<0.001$ \\
\hline MTFP1 & mitochondrial fission process 1 & 223172_s_at & -1.5 & 0.004 \\
\hline MAP2K3 & mitogen-activated protein kinase kinase 3 & 215499_at & -1.5 & 0.003 \\
\hline LRRN4CL & LRRN4 C-terminal like & 1556427_s_at & -1.4 & 0.042 \\
\hline FBXO9 & F-box protein 9 & 210638_s_at212987_at & $\begin{array}{l}-1.4 \\
-1.4\end{array}$ & $\begin{array}{l}<0.001 \\
<0.001\end{array}$ \\
\hline HERC1 & $\begin{array}{l}\text { HECT and RLD domain containing E3 ubiquitin protein ligase } \\
\text { family member } 1\end{array}$ & 218306_s_at & -1.4 & $<0.001$ \\
\hline JARID2 & jumonji, AT rich interactive domain 2 & 203297_s_at & -1.4 & $<0.001$ \\
\hline TRAK1 & trafficking protein, kinesin binding 1 & 202079_s_at & -1.4 & 0.004 \\
\hline ZNF252P & zinc finger protein 252 , pseudogene & 228200_at & -1.4 & $<0.001$ \\
\hline PRSS23 & protease, serine, 23 & 202458_at & -1.4 & 0.030 \\
\hline OLFML2B & olfactomedin-like $2 B$ & 213125_at & -1.4 & 0.049 \\
\hline MSANTD4 & Myb/SANT-like DNA-binding domain containing 4 with coiled-coils & 227418_at & -1.3 & 0.043 \\
\hline ZDHHC7 & zinc finger, DHHC-type containing 7 & 218606_at & -1.3 & $<0.001$ \\
\hline RAP2A & RAP2A, member of RAS oncogene family & 225585_at & -1.3 & 0.016 \\
\hline LRP12 & low density lipoprotein receptor-related protein 12 & 219631_at & -1.3 & 0.050 \\
\hline BMPR1A & bone morphogenetic protein receptor, type IA & 213578_at & -1.3 & 0.001 \\
\hline RNF10 & ring finger protein 10 & 207801_s_at & -1.3 & $<0.001$ \\
\hline COL5A1 & collagen, type $V$, alpha 1 & 203325_s_at & -1.3 & 0.007 \\
\hline INSIG1 & insulin induced gene 1 & 201626_at & -1.3 & 0.046 \\
\hline SLC35E3 & solute carrier family 35 , member E3 & 218988_at & -1.3 & 0.003 \\
\hline MEMO1 & dpy-30 homolog (C. elegans) /// mediator of cell motility 1 & 219065_s_at & -1.3 & 0.004 \\
\hline MYL4 & myosin, light chain 4, alkali; atrial, embryonic & 210395_x_at & -1.2 & 0.002 \\
\hline COX7A2 & cytochrome c oxidase subunit VIla polypeptide 2 (liver) & 201597_at & -1.2 & 0.019 \\
\hline MGAT4B & $\begin{array}{l}\text { mannosyl (alpha-1,3-)-glycoprotein beta-1,4-N-acetylglucosaminyltransferase, } \\
\text { isozyme B }\end{array}$ & 224598_at & -1.2 & 0.003 \\
\hline MRC2 & mannose receptor, $\mathrm{C}$ type 2 & 209280_at & -1.2 & 0.010 \\
\hline
\end{tabular}

$F D$ fold difference. ${ }^{a}$ fold differences for genes with more than one probe set were calculated as the average of the individual values, which did not differ markedly 
Table 3 Genes the expression levels of which responded to prednisolone treatment in a given direction only in patients with polymyalgia rheumatica (131 genes)

\begin{tabular}{|c|c|c|c|c|}
\hline Gene symbol & Gene name & Probe set(s) & $\mathrm{FC}^{\mathrm{a}}$ & $\mathrm{p}$ \\
\hline COL1A1 & collagen, type I, alpha 1 & 1556499_s_at & +4.7 & 0.028 \\
\hline CTGF & connective tissue growth factor & 209101_at & +2.9 & 0.012 \\
\hline MEST & mesoderm specific transcript homolog (mouse) & 202016_at & +2.7 & 0.049 \\
\hline $\mathrm{CDH} 11$ & cadherin 11, type 2, OB-cadherin (osteoblast) & 207173_x_at & +2.6 & 0.012 \\
\hline S1PR3 & sphingosine-1-phosphate receptor 3 & 228176_at & +2.5 & 0.009 \\
\hline CD248 & CD248 molecule, endosialin & 219025_at & +2.5 & 0.019 \\
\hline FBN1 & fibrillin 1 & $\begin{array}{l}\text { 202766_s_at } \\
\text { 235318_at }\end{array}$ & $\begin{array}{l}+2.4 \\
+2.1\end{array}$ & $\begin{array}{l}0.031 \\
0.017\end{array}$ \\
\hline NINJ2 & ninjurin 2 & 219594_at & +2.3 & 0.002 \\
\hline MFAP5 & microfibrillar associated protein 5 & $\begin{array}{l}\text { 209758_s_at } \\
\text { 213764_s_at } \\
\text { 213765_at }\end{array}$ & $\begin{array}{l}+2.7 \\
+2.2 \\
+2.1\end{array}$ & $\begin{array}{l}0.038 \\
0.010 \\
0.018\end{array}$ \\
\hline SH3PXD2B & SH3 and PX domains $2 \mathrm{~B}$ & 231823_s_at & +2.2 & 0.011 \\
\hline C13orf33 & chromosome 13 open reading frame 33 & 227058_at & +2.2 & 0.044 \\
\hline FOSL2 & FOS-like antigen 2 & 218880_at & +2.2 & 0.026 \\
\hline BGN & biglycan & 201261_x_at & +2.1 & 0.029 \\
\hline NEDD9 & $\begin{array}{l}\text { neural precursor cell expressed, developmentally } \\
\text { down-regulated } 9\end{array}$ & 233223_at & +2.1 & 0.004 \\
\hline COL5A2 & collagen, type $V$, alpha 2 & 221730_at & +2.0 & 0.049 \\
\hline NT5E & 5'-nucleotidase, ecto (CD73) & 203939_at & +2.0 & 0.044 \\
\hline TUBB6 & tubulin, beta 6 class $V$ & 209191_at & +2.0 & 0.031 \\
\hline SPARC & secreted protein, acidic, cysteine-rich (osteonectin) & 200665_s_at & +2.0 & 0.043 \\
\hline FN1 & fibronectin 1 & $\begin{array}{l}\text { 210495_x_at } \\
211719 \text { _x_at } \\
212464 \text { _sat } \\
\text { 216442_x_at }\end{array}$ & $\begin{array}{l}+1.9 \\
+1.9 \\
+1.9 \\
+2.0\end{array}$ & $\begin{array}{l}0.045 \\
0.042 \\
0.046 \\
0.038\end{array}$ \\
\hline GFPT2 & glutamine-fructose-6-phosphate transaminase 2 & 205100_at & +1.9 & 0.034 \\
\hline NFKBIZ & $\begin{array}{l}\text { nuclear factor of kappa light polypeptide gene enhancer } \\
\text { in B-cells inhibitor, zeta }\end{array}$ & 223217_s_at & +1.9 & 0.025 \\
\hline DCLK1 & doublecortin-like kinase 1 & 205399_at & +1.9 & 0.034 \\
\hline METRNL & meteorin, glial cell differentiation regulator-like & 225955_at & +1.9 & 0.023 \\
\hline COL1A2 & collagen, type I, alpha 2 & 229218_at & +1.8 & 0.048 \\
\hline LAMB1 & laminin, beta 1 & 201505_at & +1.8 & 0.003 \\
\hline LSP1P1 & lymphocyte-specific protein 1 pseudogene & 214110_s_at & +1.8 & 0.020 \\
\hline COL6A3 & collagen, type VI, alpha 3 & 201438_at & +1.8 & 0.003 \\
\hline GAS7 & growth arrest-specific 7 & $\begin{array}{l}\text { 202191_s_at } \\
\text { 202192_s_at }\end{array}$ & $\begin{array}{l}+1.8 \\
+1.7\end{array}$ & $\begin{array}{l}0.028 \\
0.021\end{array}$ \\
\hline ARHGAP26 & Rho GTPase activating protein 26 & 244548_at & +1.8 & 0.003 \\
\hline OLFML2B & olfactomedin-like 2B & 213125_at & +1.7 & 0.031 \\
\hline SPON2 & spondin 2, extracellular matrix protein & 218638_s_at & +1.7 & 0.002 \\
\hline COL6A1 & collagen, type VI, alpha 1 & 213428_s_at & +1.7 & 0.006 \\
\hline CILP & $\begin{array}{l}\text { cartilage intermediate layer protein, nucleotide } \\
\text { pyrophosphohydrolase }\end{array}$ & 206227_at & +1.7 & 0.012 \\
\hline OLFML3 & olfactomedin-like 3 & 218162_at & +1.7 & 0.026 \\
\hline FAM69A & family with sequence similarity 69 , member A & 213689_x_at & +1.7 & $<0.001$ \\
\hline CORO1C & coronin, actin binding protein, $1 \mathrm{C}$ & 222409_at & +1.6 & 0.020 \\
\hline MAP1B & microtubule-associated protein 1B & 226084_at & +1.6 & 0.039 \\
\hline
\end{tabular}


Table 3 Genes the expression levels of which responded to prednisolone treatment in a given direction only in patients with polymyalgia rheumatica (131 genes) (Continued)

\begin{tabular}{|c|c|c|c|c|}
\hline COL6A2 & collagen, type VI, alpha 2 & 209156_s_at & +1.6 & 0.020 \\
\hline PRKCDBP & protein kinase $C$, delta binding protein & 213010_at & +1.6 & $<0.001$ \\
\hline CLIC4 & chloride intracellular channel 4 & 201560_at & +1.6 & 0.010 \\
\hline LRRN4CL & LRRN4 C-terminal like & 1556427_s_at & +1.5 & 0.006 \\
\hline CD109 & CD109 molecule & 226545_at & +1.5 & 0.034 \\
\hline DBN1 & drebrin 1 & 202806_at & +1.5 & 0.020 \\
\hline SFXN3 & sideroflexin 3 & 220974_x_at & +1.5 & 0.016 \\
\hline TNXA / TNXB & tenascin XA (pseudogene) / tenascin XB & $\begin{array}{l}\text { 206093_x_at } \\
213451 \text { x_at } \\
216333 \text { _x_at }\end{array}$ & $\begin{array}{l}+1.5 \\
+1.5 \\
+1.5\end{array}$ & $\begin{array}{l}0.030 \\
0.034 \\
0.041\end{array}$ \\
\hline PRSS23 & protease, serine, 23 & 202458_at & +1.5 & 0.022 \\
\hline TUBA1A & tubulin, alpha 1a & 209118_s_at & +1.5 & 0.038 \\
\hline SAMHD1 & SAM domain and HD domain 1 & 235529_x_at & +1.5 & 0.024 \\
\hline ITGB1BP2 & integrin beta 1 binding protein (melusin) 2 & 219829_at & +1.5 & 0.003 \\
\hline ATP2C1 & ATPase, $\mathrm{Ca}++$ transporting, type $2 \mathrm{C}$, member 1 & 209934_s_at & +1.5 & $<0.001$ \\
\hline PXDC1 & PX domain containing 1 & 212923_s_at & +1.5 & 0.014 \\
\hline PAQR9 & progestin and adipoQ receptor family member IX & 1558322_a_at & +1.4 & 0.027 \\
\hline P4HA2 & prolyl 4-hydroxylase, alpha polypeptide II & 202733_at & +1.4 & 0.024 \\
\hline ANXA2 & annexin A2 & $\begin{array}{l}\text { 201590_x_at } \\
\text { 210427_x_at } \\
\text { 213503_x_at }\end{array}$ & $\begin{array}{l}+1.4 \\
+1.4 \\
+1.4\end{array}$ & $\begin{array}{l}0.025 \\
0.027 \\
0.032\end{array}$ \\
\hline ACVRL1 & activin A receptor type II-like 1 & 226950_at & +1.4 & 0.009 \\
\hline CHSY1 & chondroitin sulfate synthase 1 & 203044_at & +1.4 & 0.021 \\
\hline C10orf54 & chromosome 10 open reading frame 54 & 225373_at & +1.4 & 0.016 \\
\hline PLAGL1 & pleiomorphic adenoma gene-like 1 & 207943_x_at & +1.4 & 0.012 \\
\hline CTTNBP2NL & CTTNBP2 N-terminal like & 226000_at & +1.4 & 0.019 \\
\hline SYNPO2 & synaptopodin 2 & 225720_at & +1.4 & 0.013 \\
\hline ANXA2P2 & annexin A2 pseudogene 2 & 208816_x_at & +1.4 & 0.042 \\
\hline TGFB111 & transforming growth factor beta 1 induced transcript 1 & 209651_at & +1.4 & 0.043 \\
\hline ACTB & actin, beta & $\begin{array}{l}\text { 213867_x_at } \\
224594 \text { _x_at } \\
200801 \text { _x_at }\end{array}$ & $\begin{array}{l}+1.4 \\
+1.4 \\
+1.4\end{array}$ & $\begin{array}{l}0.048 \\
0.040 \\
0.033\end{array}$ \\
\hline TRIO & triple functional domain (PTPRF interacting) & $\begin{array}{l}\text { 208178_x_at } \\
\text { 209012_at }\end{array}$ & +1.4 & 0.018 \\
\hline ITGA5 & integrin, alpha 5 (fibronectin receptor, alpha polypeptide) & 201389_at & +1.4 & 0.038 \\
\hline RRBP1 & ribosome binding protein 1 homolog 180 kDa (dog) & 201204_s_at & +1.4 & 0.010 \\
\hline LASP1 & LIM and SH3 protein 1 & 200618_at & +1.4 & 0.016 \\
\hline ADNP2 & ADNP homeobox 2 & 203321_s_at & +1.3 & 0.009 \\
\hline MTFP1 & mitochondrial fission process 1 & 223172_s_at & +1.3 & 0.017 \\
\hline TP53INP2 & tumor protein p53 inducible nuclear protein 2 & 224836_at & +1.3 & 0.017 \\
\hline PDGFRB & platelet-derived growth factor receptor, beta polypeptide & 202273_at & +1.3 & 0.009 \\
\hline FBXO9 & F-box protein 9 & $\begin{array}{l}\text { 210638_s_at } \\
\text { 212987_at }\end{array}$ & $\begin{array}{l}+1.3 \\
+1.3\end{array}$ & $\begin{array}{l}0.002 \\
<0.001\end{array}$ \\
\hline VAT1 & vesicle amine transport protein 1 homolog (T. californica) & 208626_s_at & +1.3 & 0.043 \\
\hline LTBP1 & latent transforming growth factor beta binding protein 1 & 202729_s_at & +1.3 & 0.026 \\
\hline HIF1A & hypoxia inducible factor 1 , alpha subunit & 200989_at & +1.3 & 0.025 \\
\hline SH3KBP1 & SH3-domain kinase binding protein 1 & 1554168_a_at & +1.3 & 0.044 \\
\hline
\end{tabular}


Table 3 Genes the expression levels of which responded to prednisolone treatment in a given direction only in patients with polymyalgia rheumatica (131 genes) (Continued)

\begin{tabular}{|c|c|c|c|c|}
\hline & & 223082_at & +1.3 & 0.027 \\
\hline JARID2 & jumonji, AT rich interactive domain 2 & 203297_s_at & +1.3 & 0.007 \\
\hline ACTG1 & actin, gamma 1 & 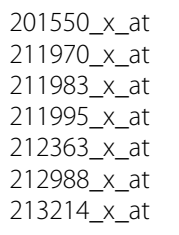 & $\begin{array}{l}+1.3 \\
+1.3 \\
+1.3 \\
+1.3 \\
+1.3 \\
+1.3 \\
+1.3\end{array}$ & $\begin{array}{l}0.015 \\
0.009 \\
0.031 \\
0.013 \\
0.020 \\
0.017 \\
0.021\end{array}$ \\
\hline MAP2K3 & mitogen-activated protein kinase kinase 3 & 215499_at & +1.3 & 0.021 \\
\hline MEMO1 & mediator of cell motility 1 & 219065_s_at & +1.3 & 0.012 \\
\hline EZR & ezrin & 208623_s_at & +1.3 & 0.002 \\
\hline BPGM & 2,3-bisphosphoglycerate mutase & 203502_at & +1.2 & 0.036 \\
\hline TUBB & tubulin, beta class I & 212320_at & +1.2 & 0.039 \\
\hline DDAH1 & dimethylarginine dimethylaminohydrolase 1 & 209094_at & +1.2 & 0.033 \\
\hline BDNF & brain-derived neurotrophic factor & 244503_at & -3.1 & 0.001 \\
\hline SLC25A34 & solute carrier family 25 , member 34 & $\begin{array}{l}\text { 1559977_a_at } \\
\text { 232245_at }\end{array}$ & $\begin{array}{l}-1.9 \\
-1.9\end{array}$ & $\begin{array}{l}0.006 \\
0.009\end{array}$ \\
\hline SVIP & small VCP/p97-interacting protein & 230285_at & -1.7 & 0.004 \\
\hline VPS8 & vacuolar protein sorting 8 homolog (S. cerevisiae) & 239917_at & -1.6 & $<0.001$ \\
\hline PIAS2 & protein inhibitor of activated STAT, 2 & 244633_at & -1.6 & 0.011 \\
\hline LOC100507303 & uncharacterized LOC100507303 & 228049_x_at & -1.6 & 0.004 \\
\hline RPL37 & ribosomal protein $L 37$ & 224763_at & -1.5 & $<0.001$ \\
\hline TMTC1 & transmembrane and tetratricopeptide repeat containing 1 & $\begin{array}{l}\text { 226322_at } \\
\text { 226931_at }\end{array}$ & $\begin{array}{l}-1.4 \\
-1.6\end{array}$ & $\begin{array}{l}0.005 \\
<0.001\end{array}$ \\
\hline MLYCD & malonyl-CoA decarboxylase & 218869_at & -1.5 & 0.004 \\
\hline UCP3 & uncoupling protein 3 (mitochondrial, proton carrier) & 207349_s_at & -1.5 & 0.016 \\
\hline TUBD1 & tubulin, delta 1 & 231853_at & -1.4 & 0.003 \\
\hline BCKDHA & $\begin{array}{l}\text { branched chain keto acid dehydrogenase E1, alpha } \\
\text { polypeptide }\end{array}$ & 202331_at & -1.4 & 0.004 \\
\hline TRIM39 & tripartite motif containing 39 & 222732_at & -1.4 & 0.002 \\
\hline ZNF331 & zinc finger protein 331 & 219228_at & -1.4 & 0.003 \\
\hline NRBF2 & nuclear receptor binding factor 2 & 223650_s_at & -1.4 & 0.021 \\
\hline GTF2H5 & general transcription factor IIH, polypeptide 5 & 244294_at & -1.4 & 0.007 \\
\hline $\mathrm{FMO} 2$ & flavin containing monooxygenase 2 (non-functional) & 228268_at & -1.4 & 0.002 \\
\hline TMEM18 & transmembrane protein 18 & 225489_at & -1.4 & 0.028 \\
\hline HSDL2 & Hydroxysteroid dehydrogenase like 2 & 215436_at & -1.4 & 0.006 \\
\hline N4BP2L1 & NEDD4 binding protein 2-like 1 & 213375_s_at & -1.4 & 0.033 \\
\hline PEBP4 & phosphatidylethanolamine-binding protein 4 & 227848_at & -1.4 & 0.009 \\
\hline RANBP9 & RAN binding protein 9 & 216125_s_at & -1.4 & 0.002 \\
\hline ST3GAL5 & ST3 beta-galactoside alpha-2,3-sialyltransferase 5 & 203217_s_at & -1.3 & 0.003 \\
\hline ACADSB & acyl-CoA dehydrogenase, short/branched chain & 226030_at & -1.3 & 0.006 \\
\hline RNF114 & ring finger protein 114 & $\begin{array}{l}\text { 200867_at } \\
\text { 200868_s_at } \\
\text { 211678_s_at }\end{array}$ & $\begin{array}{l}-1.3 \\
-1.3 \\
-1.2\end{array}$ & $\begin{array}{l}0.020 \\
0.030 \\
0.041\end{array}$ \\
\hline MRPS2 & mitochondrial ribosomal protein $\mathrm{S} 2$ & 218001_at & -1.3 & 0.006 \\
\hline TMEM50B & transmembrane protein 50B & 219600_s_at & -1.3 & 0.027 \\
\hline EIF3G & eukaryotic translation initiation factor 3 , subunit $G$ & 208887_at & -1.3 & 0.005 \\
\hline
\end{tabular}


Table 3 Genes the expression levels of which responded to prednisolone treatment in a given direction only in patients with polymyalgia rheumatica (131 genes) (Continued)

\begin{tabular}{|c|c|c|c|c|}
\hline PSIP1 & PC4 and SFRS1 interacting protein 1 & 209337_at & -1.3 & 0.007 \\
\hline PTP4A1 & protein tyrosine phosphatase type IVA, member 1 & 200732_s_at & -1.3 & $<0.001$ \\
\hline EIF4B & eukaryotic translation initiation factor $4 \mathrm{~B}$ & 211937_at & -1.3 & 0.015 \\
\hline FAM184B & family with sequence similarity 184 , member $B$ & 235288_at & -1.3 & 0.042 \\
\hline CNNM3 & cyclin M3 & 229031_at & -1.3 & 0.011 \\
\hline RERE & arginine-glutamic acid dipeptide (RE) repeats & 200940_s_at & -1.3 & 0.008 \\
\hline ZNF195 & zinc finger protein 195 & 204234_s_at & -1.3 & 0.002 \\
\hline SNRPA & small nuclear ribonucleoprotein polypeptide A & 201770_at & -1.3 & 0.025 \\
\hline TM4SF18 & transmembrane $4 \mathrm{~L}$ six family member 18 & 230061_at & -1.3 & 0.033 \\
\hline RPL36AL & ribosomal protein L36a-like & 207585_s_at & -1.2 & 0.008 \\
\hline RBBP6 & retinoblastoma binding protein 6 & 212783_at & -1.2 & 0.025 \\
\hline TSFM & Ts translation elongation factor, mitochondrial & 214331_at & -1.2 & 0.019 \\
\hline POLR1B & polymerase (RNA) I polypeptide B, $128 \mathrm{kDa}$ & 223403_s_at & -1.2 & 0.018 \\
\hline NPM1 & nucleophosmin (nucleolar phosphoprotein B23, numatrin) & 221691_x_at & -1.2 & 0.022 \\
\hline OXA1L & oxidase (cytochrome c) assembly 1-like & 208717_at & -1.2 & 0.027 \\
\hline RSBN1 & round spermatid basic protein 1 & 213694_at & -1.2 & 0.016 \\
\hline AKR7A2 & aldo-keto reductase family 7 , member $\mathrm{A} 2$ & 202139_at & -1.2 & 0.002 \\
\hline RORA & RAR-related orphan receptor $A$ & 226682_at & -1.2 & 0.044 \\
\hline DFFA & DNA fragmentation factor, $45 \mathrm{kDa}$, alpha polypeptide & 226116_at & -1.2 & 0.016 \\
\hline
\end{tabular}

FC, fold change. Entries in bold indicate that genes also responded significantly (but in the opposite direction) in control subjects. Responses in controls for both

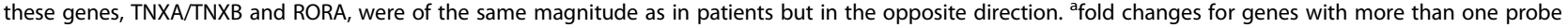
set were calculated as the average of the individual values, which did not differ markedly

measured using quantitative real-time PCR (qRT-PCR). Moreover, mRNA levels for additional genes (Table 5) that did not differ using microarrays, but which were of particular interest in elucidating the PMR disease mechanisms, were included in the qRT-PCR analysis.

From 9 patient samples and 9 control subject samples, cDNA was synthesized using Omniscript reverse transcriptase (Qiagen, Hilden, Germany) from $500 \mathrm{ng}$ total RNA (same pool as used in the microarray runs) in $20 \mu \mathrm{l}$. For each target mRNA, $0.25 \mu \mathrm{l}$ cDNA was amplified in $25 \mu \mathrm{l}$ Quantitect SYBR Green Master Mix (Qiagen) with corresponding primers (100 nM of both antisense and sense primers, Table 6) on a Stratagene MX3000P RTPCR instrument (Stratagene, La Jolla, CA, US).

The applied thermal profile was as follows: $95^{\circ} \mathrm{Celsius,}$ $10 \min -\left(95{ }^{\circ} \mathrm{C}, 15 \mathrm{~s}-58{ }^{\circ} \mathrm{C}, 30 \mathrm{~s}-63^{\circ} \mathrm{C}, 90 \mathrm{~s}\right) \times 50-95{ }^{\circ} \mathrm{C}$, $60 \mathrm{~s}-55^{\circ} \mathrm{C}$, $30 \mathrm{~s}-95^{\circ} \mathrm{C}, 60 \mathrm{~s}$. Standard curves were made using dilution series of a cDNA pool and related to the threshold cycles $\left(\mathrm{C}_{\mathrm{t}}\right)$ at the $63{ }^{\circ} \mathrm{C}$ step at which the signal intensity was acquired. To ensure specificity, melting curves were analyzed post amplification (at the $55{ }^{\circ} \mathrm{C}$ to $95{ }^{\circ} \mathrm{C}$ step). The $\mathrm{C}_{\mathrm{t}}$ values for the samples were converted to relative values using the standard curves and normalized to the internal "housekeeping" control, ribosomal protein P0 (RPLP0). Microarray analysis confirmed that the RPLP0 mRNA level is stable under the current conditions and therefore suitable as the normalizer.

\section{Statistics}

Statistical methods used in the evaluation of the microarray data are described above. Data are reported in compliance with the guidelines for minimum information about a microarray experiment (MIAME).

Statistical analyses of qRT-PCR and anthropometric data as well as of ESR and CRP levels were performed using SPSS software version 20.0 for Macintosh. qRTPCR data were log-transformed. Statistically significant differences were detected using Student's $t$ tests, paired or unpaired as applicable. Identical conclusions were achieved with standard non-parametric tests. Pvalues less than 0.05 were considered significant in two-tailed testing.

\section{Results}

Clinical characteristics for all participants are given in Table 1. In all of the PMR patients, treatment with prednisolone abolished symptoms within a few days, supporting the PMR diagnosis; at day 15, ESR and CRP levels were markedly reduced in the patients and did no longer differ significantly from values in controls (Table 1). 
Table 4 Genes the expression levels of which differed between untreated patients with polymyalgia rheumaticaand untreated controls (FD), and which responded to prednisolone treatment in the patients (FC) (44 genes)

\begin{tabular}{|c|c|c|c|c|c|}
\hline Gene symbol & Gene name & $\mathrm{FD}^{\mathrm{a}}$ & $\mathrm{p}$ & $\mathrm{FC}^{\mathrm{b}}$ & $\mathrm{p}$ \\
\hline BDNF & brain-derived neurotrophic factor & +1.8 & 0.016 & -3.1 & 0.001 \\
\hline SVIP & small VCP/p97-interacting protein & +1.7 & 0.002 & -1.7 & 0.004 \\
\hline TM4SF18 & transmembrane $4 \mathrm{~L}$ six family member 18 & +1.5 & 0.007 & -1.3 & 0.033 \\
\hline TMTC1 & transmembrane and tetratricopeptide repeat containing 1 & +1.5 & 0.001 & -1.5 & 0.003 \\
\hline TMEM18 & transmembrane protein 18 & +1.5 & 0.008 & -1.4 & 0.028 \\
\hline N4BP2L1 & NEDD4 binding protein 2-like 1 & +1.5 & 0.019 & -1.4 & 0.033 \\
\hline FMO2 & flavin containing monooxygenase 2 (non-functional) & +1.5 & 0.002 & -1.4 & 0.012 \\
\hline RPL37 & ribosomal protein $\mathrm{L} 37$ & +1.5 & $<0.001$ & -1.5 & $<0.001$ \\
\hline FAM184B & family with sequence similarity 184 , member B & +1.4 & 0.013 & -1.3 & 0.042 \\
\hline LOC100507303 & uncharacterized LOC100507303 & +1.4 & 0.019 & -1.6 & 0.004 \\
\hline RNF114 & ring finger protein 114 & +1.3 & 0.016 & -1.3 & 0.030 \\
\hline RERE & arginine-glutamic acid dipeptide (RE) repeats & +1.3 & 0.003 & -1.3 & 0.008 \\
\hline TUBD1 & tubulin, delta 1 & +1.3 & 0.003 & -1.4 & 0.003 \\
\hline ZNF195 & zinc finger protein 195 & +1.3 & 0.003 & -1.3 & 0.002 \\
\hline DFFA & DNA fragmentation factor, $45 \mathrm{kDa}$, alpha polypeptide & +1.3 & 0.010 & -1.2 & 0.016 \\
\hline RBBP6 & retinoblastoma binding protein 6 & +1.3 & 0.004 & -1.2 & 0.025 \\
\hline NPM1 & nucleophosmin (nucleolar phosphoprotein B23, numatrin) & +1.3 & 0.011 & -1.2 & 0.022 \\
\hline EIF4B & eukaryotic translation initiation factor $4 \mathrm{~B}$ & +1.3 & 0.017 & -1.3 & 0.015 \\
\hline RSBN1 & round spermatid basic protein 1 & +1.2 & 0.003 & -1.2 & 0.016 \\
\hline PSIP1 & PC4 and SFRS1 interacting protein 1 & +1.2 & 0.010 & -1.3 & 0.007 \\
\hline EIF3G & eukaryotic translation initiation factor 3 , subunit $G$ & +1.2 & 0.006 & -1.3 & 0.005 \\
\hline PXDC1 & PX domain containing 1 & +1.2 & 0.042 & +1.5 & 0.014 \\
\hline BCKDHA & branched chain keto acid dehydrogenase E1, alpha polypeptide & +1.2 & 0.024 & -1.4 & 0.004 \\
\hline AKR7A2 & aldo-keto reductase family 7 , member A2 & +1.2 & 0.010 & -1.2 & 0.002 \\
\hline MRPS2 & mitochondrial ribosomal protein $\mathrm{S} 2$ & +1.2 & 0.018 & -1.3 & 0.006 \\
\hline RORA & RAR-related orphan receptor A & +1.2 & 0.049 & -1.2 & 0.044 \\
\hline RPL36AL & ribosomal protein L36a-like & +1.2 & 0.011 & -1.2 & 0.008 \\
\hline PAQR9 & progestin and adipoQ receptor family member IX & -2.0 & $<0.001$ & +1.4 & 0.027 \\
\hline FAM69A & family with sequence similarity 69 , member $A$ & -1.8 & 0.001 & +1.7 & $<0.001$ \\
\hline TP53INP2 & tumor protein p53 inducible nuclear protein 2 & -1.8 & $<0.001$ & +1.3 & 0.017 \\
\hline SH3KBP1 & SH3-domain kinase binding protein 1 & -1.8 & 0.002 & +1.3 & 0.035 \\
\hline NINJ2 & ninjurin 2 & -1.7 & 0.039 & +2.3 & 0.002 \\
\hline MEST & mesoderm specific transcript homolog (mouse) & -1.7 & 0.010 & +2.7 & 0.049 \\
\hline ITGB1BP2 & integrin beta 1 binding protein (melusin) 2 & -1.6 & $<0.001$ & +1.5 & 0.003 \\
\hline BPGM & 2,3-bisphosphoglycerate mutase & -1.5 & $<0.001$ & +1.2 & 0.036 \\
\hline MTFP1 & mitochondrial fission process 1 & -1.5 & 0.004 & +1.3 & 0.017 \\
\hline MAP2K3 & mitogen-activated protein kinase kinase 3 & -1.5 & 0.003 & +1.3 & 0.021 \\
\hline LRRN4CL & LRRN4 C-terminal like & -1.4 & 0.042 & +1.5 & 0.006 \\
\hline FBXO9 & F-box protein 9 & -1.4 & $<0.001$ & +1.3 & 0.001 \\
\hline JARID2 & jumonji, AT rich interactive domain 2 & -1.4 & $<0.001$ & +1.3 & 0.007 \\
\hline PRSS23 & protease, serine, 23 & -1.4 & 0.030 & +1.5 & 0.022 \\
\hline OLFML2B & olfactomedin-like 2B & -1.4 & 0.049 & +1.7 & 0.031 \\
\hline MEMO1 & mediator of cell motility 1 & -1.3 & 0.004 & +1.3 & 0.012 \\
\hline
\end{tabular}

FD fold difference, $F C$ fold change

a + and -; expression levels were higher and lower, respectively, in patients with polymyalgia rheumatica than in controls before treatment with prednisolone b + and -; expression levels increased and decreased, respectively, in patients with polymyalgia rheumatica after treatment with prednisolone Entry in bold indicates that the gene also responded significantly to prednisolone in controls. The response in controls for the RORA gene was of the same magnitude as in patients but in the opposite direction 
Table 5 Quantitative RT-PCR fold differences between untreated patients with polymyalgia rheumatica (PMR) and non-PMR controls, and fold changes between treated and untreated PMR patients

\begin{tabular}{|c|c|c|c|c|}
\hline \multirow{2}{*}{$\frac{\text { Gene symbol }}{\text { (probe name) }}$} & \multicolumn{2}{|l|}{ Fold differences $^{\mathrm{b}}$} & \multicolumn{2}{|c|}{ Fold changes ${ }^{c}$} \\
\hline & qRT-PCR & Microarray $^{\mathrm{a}}$ & qRT-PCR & Microarray $^{\mathrm{a}}$ \\
\hline \multicolumn{5}{|c|}{ Genes that differed in microarray testing in at least one comparison } \\
\hline BDNF & $+1.90^{*}$ & $+1.80 *$ & $-1.58 * *$ & $-3.1 * *$ \\
\hline COL5A1 & $-1.33 \mathrm{~ns}$ & $-1.30 * *$ & $+1.73 \mathrm{~ns}$ & $+2.30 \mathrm{~ns}$ \\
\hline EIF4B & $+1.63 p=0.0504$ & +1.30 * & $-1.23 *$ & $-1.30 *$ \\
\hline MARK4 & $+1.32 \mathrm{~ns}$ & $+1.30 * *$ & $-1.24 *$ & $-1.15 \mathrm{~ns}$ \\
\hline MTFP1 & $+1.00 \mathrm{~ns}$ & $-1.50 * *$ & $+1.33 *$ & $+1.30 *$ \\
\hline NPM1 & $+1.38 * *$ & $+1.30 *$ & $-1.09 \mathrm{~ns}$ & $-1.22 *$ \\
\hline PRSS23 & $-1.21 \mathrm{~ns}$ & $-1.40 *$ & $+1.27 \mathrm{~ns}$ & $+1.51 *$ \\
\hline TFRC & $-1.63 \mathrm{~ns}$ & $-3.00 *$ & $+1.17 \mathrm{~ns}$ & $+1.76 \mathrm{~ns}$ \\
\hline TUBD1 & $+1.26 * *$ & $+1.30 * *$ & $-1.08 \mathrm{~ns}$ & $-1.40 * *$ \\
\hline \multicolumn{5}{|c|}{ Genes that did not differ in microarray testing } \\
\hline $\begin{array}{l}\text { ACTA1 } \\
\text { (203872_at) }\end{array}$ & $-1.03 \mathrm{~ns}$ & $-1.02 \mathrm{~ns}$ & $1.06 \mathrm{~ns}$ & $+1.00 \mathrm{~ns}$ \\
\hline $\begin{array}{l}\text { DES }^{a} \\
\text { (216947_at } \\
\text { 202222_s_at } \\
\text { 214027_x_at) }\end{array}$ & $+1.16 \mathrm{~ns}$ & $+1.00 \mathrm{~ns}$ & $-1.07 \mathrm{~ns}$ & $+1.00 \mathrm{~ns}$ \\
\hline $\begin{array}{l}\text { IL6 } \\
\text { (205207_at) }\end{array}$ & +4.54 * & $+1.02 \mathrm{~ns}$ & $-3.25 *$ & $+1.02 \mathrm{~ns}$ \\
\hline $\begin{array}{l}\text { TNFA } \\
\text { (207113_s_at) }\end{array}$ & $+1.31 \mathrm{~ns}$ & $+1.00 \mathrm{~ns}$ & $-1.31 \mathrm{~ns}$ & $-1.00 \mathrm{~ns}$ \\
\hline $\begin{array}{l}\text { TUBA8 } \\
\text { (220069_at) }\end{array}$ & $-1.02 \mathrm{~ns}$ & $-1.02 \mathrm{~ns}$ & $+1.10 \mathrm{~ns}$ & +1.00 ns \\
\hline
\end{tabular}

qRT-PCR quantitative real-time $P C R$

${ }^{*} p<0.05$. ${ }^{* *} p<0.01$. ns, not statistically significant. Data are geometric means

a Microarray numbers were calculated as the mean of the individual probe values

${ }^{\mathrm{b}}+$ and - , expression levels were higher and lower, respectively, in patients with polymyalgia rheumatica than in controls before treatment with prednisolone

${ }^{c}+$ and -, expression levels increased and decreased, respectively, in patients with polymyalgia rheumatica after treatment with prednisolone

Control subjects had normal ESR and CRP values both before and after treatment (Table 1).

\section{Differential expression of genes in untreated PMR patients vs controls}

565 transcripts were differentially expressed between patients and controls or before vs after treatment with prednisolone, reflecting either main effect or interaction. Among these transcripts, 165 genes fulfilled at least one of the 2 criteria (Methods) that define the potentially, clinically relevant genes.

Of the 165 genes, expression levels of 78 genes differed between patients and controls before treatment (Fig. 1, Table 2). Among these genes, 41 genes were upregulated in the patients (mean fold difference: 1.4; range: 1.2-1.8), while 37 were downregulated (mean fold difference: 1.5 ; range: $1.2-3.0$ ).

In this subset, the biological function (Fig. 2) of the 78 genes as identified by the DAVID functional annotation clusters (19 clusters in total) included translation/protein biosynthesis ( 2 clusters, enrichment scores 0.8 and 0.62 [data not shown), transcription/regulation of transcription ( 2 clusters, enrichment score 0.69 and 0.4 [data not shown), nuclear transport and protein transport (enrichment score 0.83), and $\mathrm{SH} 3$ domain binding properties (enrichment score 1.15 [data not shown).

\section{Genes responding to prednisolone in PMR patients}

Expression of 131 of the total 165 genes responded to prednisolone treatment in patients (Fig. 1 and Table 3); of these genes, two responded significantly to treatment in controls, however in the opposite direction to that seen in patients. Of the 131 genes, the expression of 84 genes was up-regulated upon treatment (mean fold change: 1.7; range: 1.2-4.7); 47 genes were down-regulated (mean fold difference: 1.4; range: $1.2-3.1$ ). In this subset, out of a total of 62 DAVID-identified clusters, the clusters of interesting biological function and high enrichment scores (Fig. 3) included extracellular matrix organization and cell adhesion (2 highly enriched clusters, enrichment scores 5.58 and 4.11 [not shown in Fig. 3]), cytoskeleton/microtubule organization ( 2 clusters, enrichment scores 2.38 and 1.62 [not shown in Fig. 3]), and actin filament/cytoskeleton associated processes (1 cluster, enrichment score 1.57).

Genes differentially expressed in untreated PMR patients vs controls and also responding to prednisolone in patients

Among all 165 differentially expressed genes were 44 genes, the expression levels of which differed between untreated patients and controls and which in patients only also responded to prednisolone treatment in a given direction (Fig. 1 and Table 4). Of these 44 genes, the expression levels of 28 genes were higher in untreated patients than in untreated controls (mean fold difference: 1.4; range: 1.2-1.8); the expression levels of 16 genes were lower (mean fold difference: 1.4; range: 1.2-2.0). Upon prednisolone treatment, the expression levels of 27 were down-regulated in patients (mean fold change: 1.4; range: 1.2-3.1), whereas 17 genes were up-regulated (mean fold change: 1.5; range: 1.2-2.7). None of the 44 genes responded significantly to prednisolone treatment in control subjects.

In this subset, out of a total of 8 DAVID-identified clusters, the clusters with the highest enrichment scores (Fig. 4) comprised genes with transcription regulation (2 clusters, enrichment scores 1.59 and 1.17 (data not shown) and protein translation/biosynthesis (2 clusters, enrichment score 0.63 and 0.59 (data not shown) properties. 
Table 6 qRT-PCR primer sequences

\begin{tabular}{|c|c|c|}
\hline Gene & Sense & Antisense \\
\hline ACTA1 & GCCGTGTTCCCGTCCATCGT & TTCAGGGTCAGGATACCTCTCTTGCT \\
\hline BDNF & GAGGGGAGCTGAGCGTGTGTG & TTITTGTTGCCGCCGTTACCC \\
\hline COL5A1 & CGCCGACACCTCCAACTCCTC & CTCAGTGAACTCCCCCTCCAA \\
\hline DES & CCATCCAGACCTACTCTGCCCTC & TTGGTATGGACCTCAGAACCCCTTT \\
\hline EIF4B & CGTCAGCTGGATGAGCCAAAA & GTCCTCGACCGTTCCCGTTCC \\
\hline IL6 & GAGGCACTGGCAGAAAACAACC & CCTCAAACTCCAAAAGACCAGTGATG \\
\hline MARK4 & AGATCCCAGAGCGGCGGAAG & GGGTCATCATGCTAGGAGGGAGGTT \\
\hline MTFP1 & AAGGCAAGAAGGCTGGAGAGGTG & ACAGAGGCTAGAGCCTGCCATACAAA \\
\hline NPM1 & GGTTTCCCTTGGGGGCTTTG & GCACTGGCCCTGAACCACACTT \\
\hline PRSS23 & CAGCGGGTCTGGGGTCTATG & GCCAATAATTITCGCTCCCACTTCT \\
\hline TUBD1 & TGATTGTTGGGAAGGCATGGA & CAACAACCTGCTCTAATGACGTGAAA \\
\hline TFRC & TCGGGAATGCTGAGAAAACAGACA & TाTTGGAGATACGTAGGGAGAGAGGAA \\
\hline TNFA & TTCCCCAGGGACCTCTCTCTAATC & GAGGGTTTGCTACAACATGGGCTAC \\
\hline TUBA8 & GCCCAAGGATGTGAATGTCGCT & GGTCGGGGGCTGGTAGTTGATG \\
\hline RPLPO & GGAAACTCTGCATTCTCGCTTCCT & CCAGGACTCGTTTGTACCCGTTG \\
\hline
\end{tabular}

qRT-PCR quantitative real-time PCR

The primer set sequence for BDNF provided in Table 6 recognizes all BDNF isoforms; using this primer set, the results presented in Table 5 were obtained. The BDNF mRNA levels were also assessed with qRT-PCR using a BDNF primer set that specifically recognizes the BDNF isoform that is recognized by the probe on the used microarray; the results (fold difference $+1.53, p<0.1$; fold change $-2.4, p<0.01$ ) from this additional assessment were very similar to the results presented in Table 5

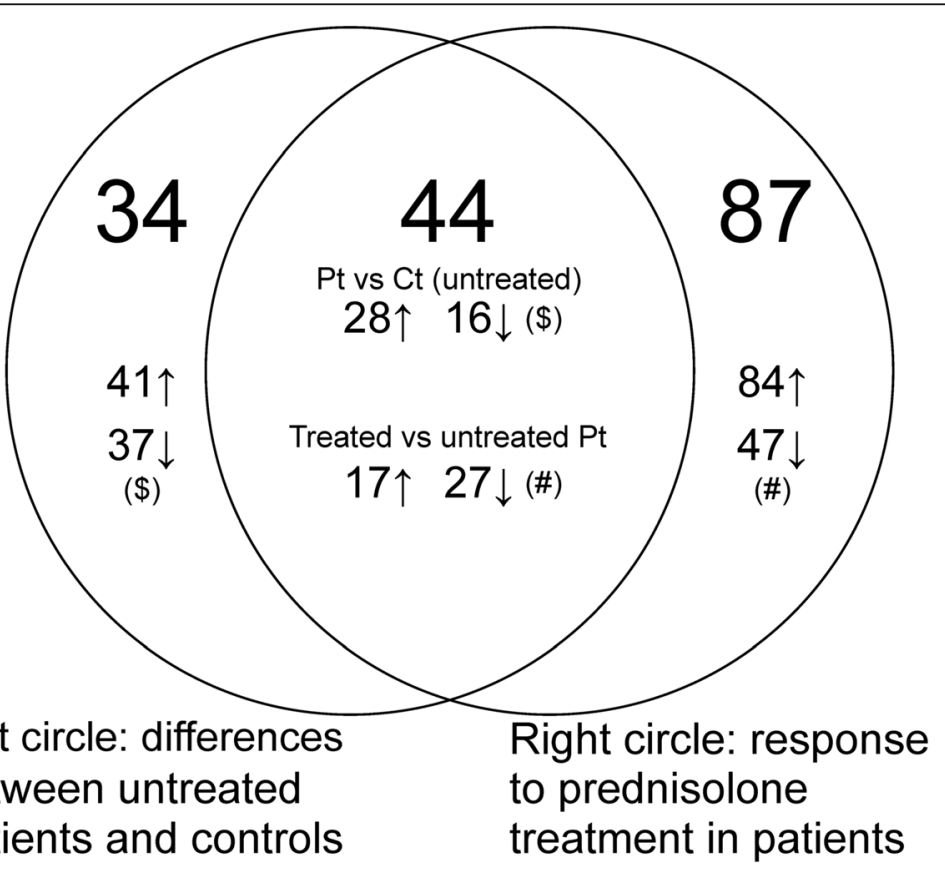

(\$)^ and $\downarrow$; expression levels were higher and lower, respectively, in patients with PMR than in controls before treatment with prednisolone.

(\#) $\uparrow$ and $\downarrow$; expression levels increased and decreased, respectively, in patients with PMR after treatment with prednisolone.

Fig. 1 Venn-diagram showing 1. the number of genes that differed between untreated patients with polymyalgia rheumatica (PMR) and non-PMR controls (left circle, $34+44$ genes) and 2. the number of genes that responded to treatment with prednisolone in a given direction in patients with PMR only (right circle, $44+87$ genes). The overlap of the two circles includes the number of genes which fulfilled both criteria 1 and 2 (44) 


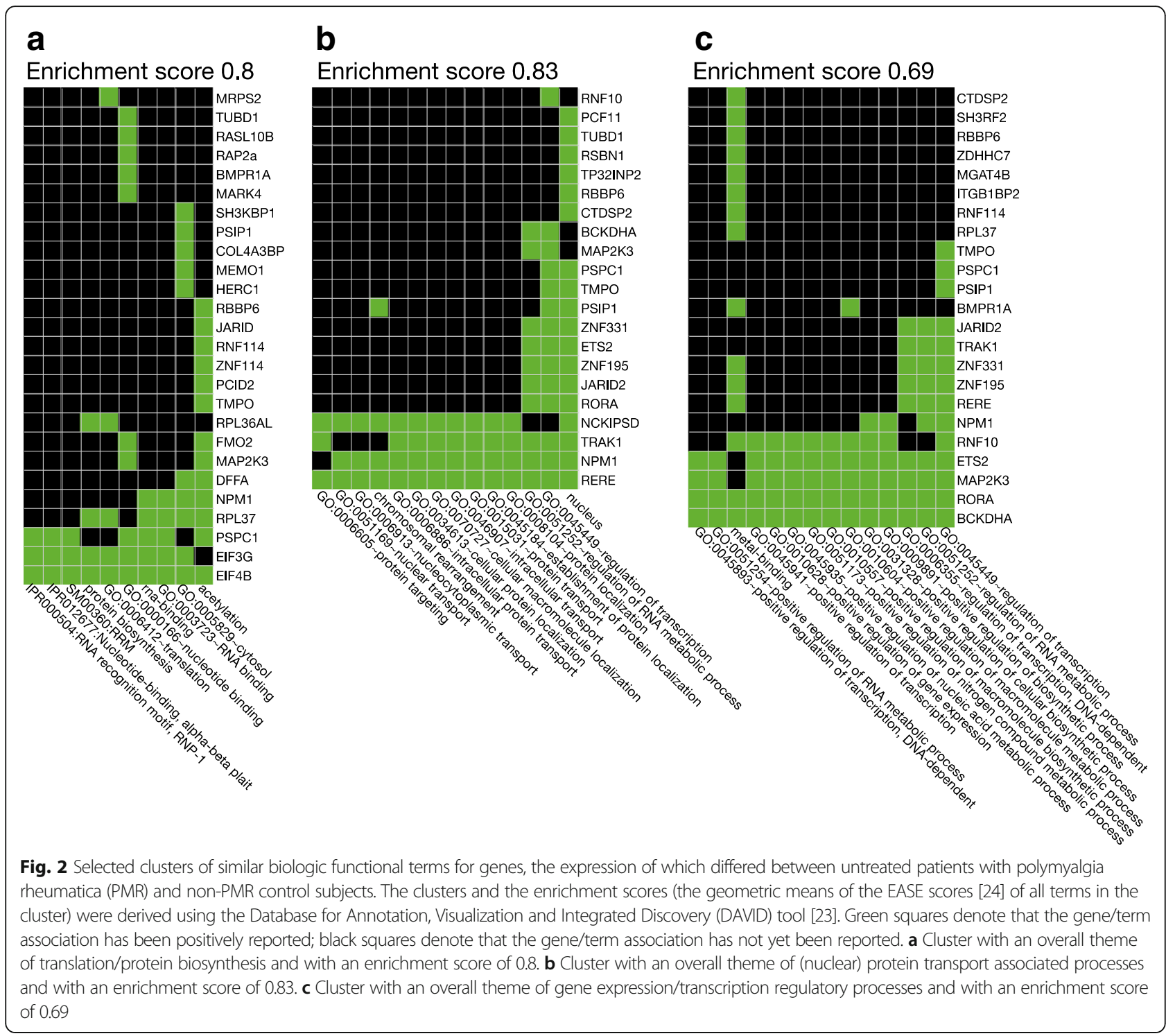

\section{qRT-PCR}

To validate the levels found using microarrays, the expression of some of the genes were measured using qRT-PCR (Tables 5 and 6, and Fig. 5).

Nine genes that fulfilled criterion 1 or criterion 2 according to microarray analysis were examined with qRTPCR (Table 5 and Fig. 5b); 8 of the 9 genes were always regulated in the same direction as found using microarrays. However, for the comparison of patients and controls before treatment (criterion 1), the expression fold differences of 5 genes (COL5A1, MARK4, MTFP1, PRSS23, and TRFC), which were statistically significant in the microarray analysis, did not reach significance using qRT-PCR $(p>0.05)$. For the treated vs untreated patients comparison (criterion 2), the fold changes for NPM1, PRSS23 and TUBD1 were significant in the microarray but not in the
qRT-PCR, whereas the fold change for MARK4 was significant only in qRT-PCR analysis. The fold changes for COL5A1 and TRFC were not statistically significant $(p>0.05)$ in the microarray nor in the qRT-PCR analysis.

Moreover, the expression levels of 5 genes (Table 5) of potential interest in PMR that did not differ in the microarray analysis were measured using qRT-PCR. Expression levels of IL-6 (Fig. 5a), which did not differ in the microarray experiments (FD and $\mathrm{FC}<1.1$ ), markedly differed both between untreated patients and controls (FD 4.54, $p<0.05$ ) and between patients before and after treatment $(\mathrm{FC}-3.25, p<0.05)$ using qRT-PCR (Table 5). The remaining four genes were found to differ neither between untreated patients and controls nor between patients before and after treatment with either method. 


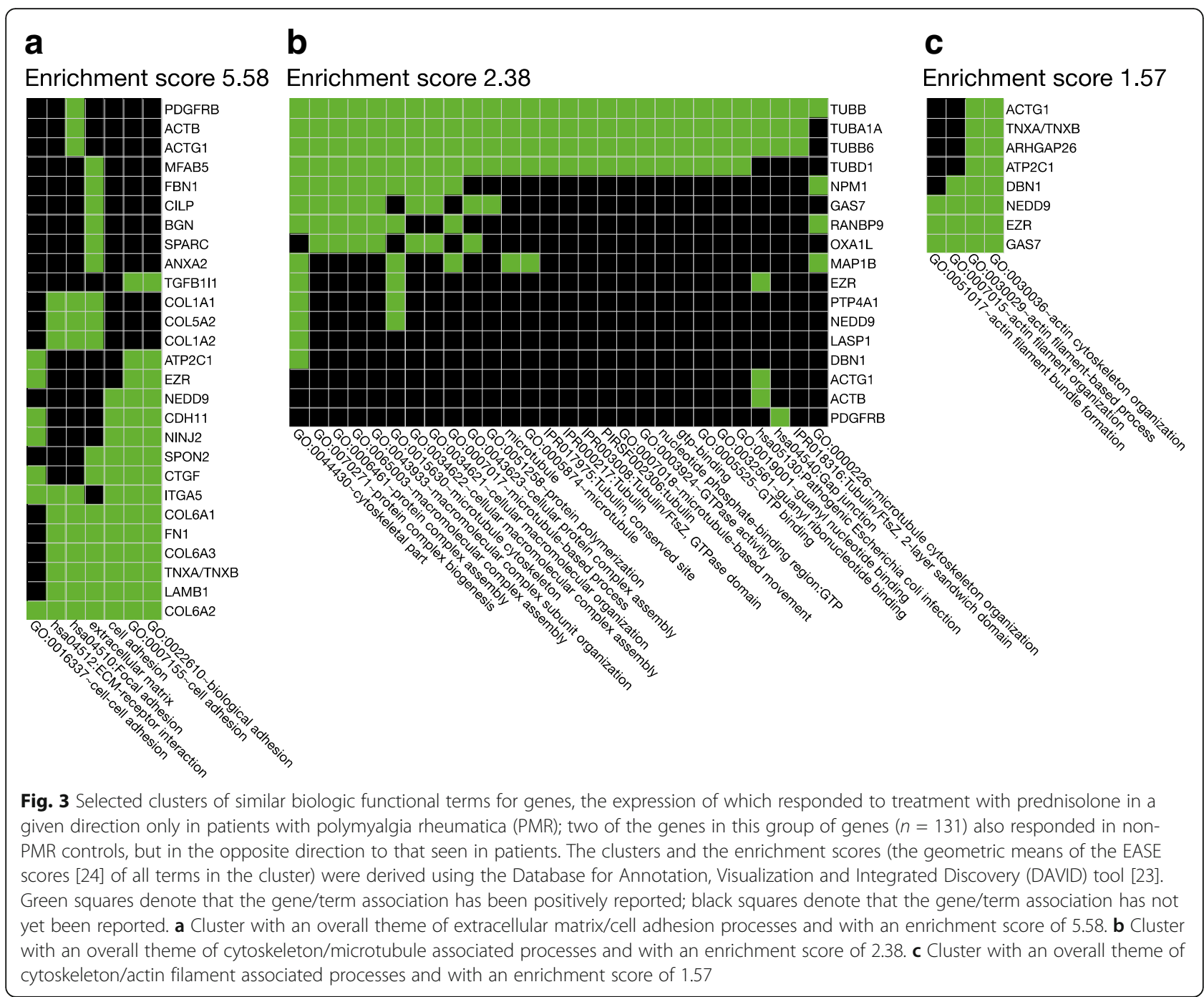

\section{Discussion}

In the present study, the gene expression in skeletal muscle was measured for the first time in patients with PMR and in non-PMR, matched controls subjects before and after brief, symptom-relieving prednisolone treatment using DNA microarrays. Microarray findings were supplemented by testing of the expression levels of selected genes with qRT-PCR, which was also used to accurately measure expression levels of genes of particular interest. In all subjects, biopsies were obtained from the trapezius muscle. Before treatment, patients had marked clinical symptoms, including trapezius myalgia and tenderness, as well as elevated ESR and levels of CRP; upon treatment, paraclinical parameters had normalized and clinical symptoms had disappeared.

Subjects were studied in 2008; thus, we were not able to use the most recent PMR criteria, which were published in 2012 [17]. However, the latter criteria are still provisional and awaiting further validation, and, in the most recent reviews of PMR, the Chuang criteria are mentioned on par with the newer provisional criteria [2, $3,8,17]$. The two criteria sets are very similar; however, the fact that the demand for a high ESR is stricter in the Chuang criteria implies that the patients in the present study would also be accepted with the new criteria.

A total of 565 genes were differentially expressed across all groups. In general, when measured by microarray, fold differences and fold changes in expression were modest, ranging from 1.2 (cut-off value) to 1.4 for most genes. Despite the relatively modest differences in gene expression levels, gene function analysis indicated that even these small differences may have a pathophysiological and phenotypic impact in PMR. A few genes were regulated more markedly, with fold differences and changes in the range of 2 to 4 . In the microarray measurements, none of the genes that usually are associated with PMR [12], for example genes encoding proteins involved in inflammation, e.g. IL-6, were 


\section{a}

\section{Enrichment score 1.59}

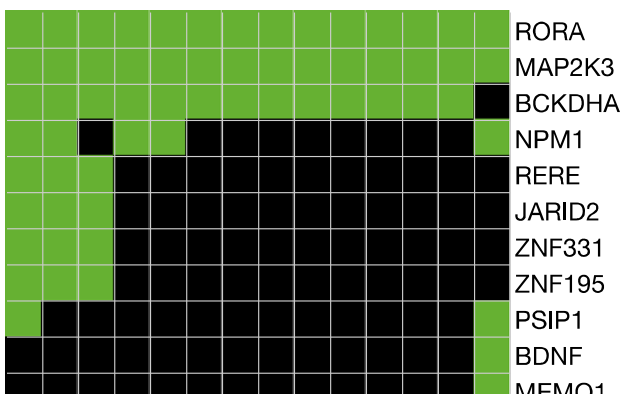

b

\section{Enrichment score 0.63}

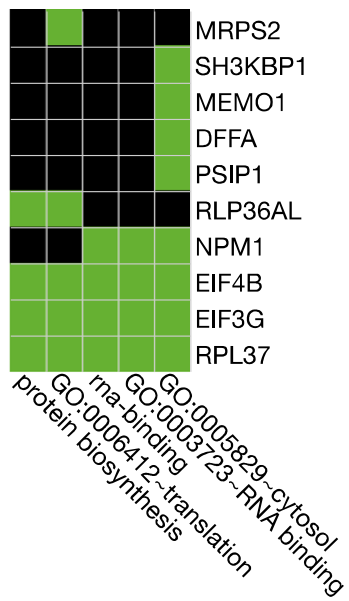

Fig. 4 Selected clusters of similar biologic functional terms for genes, the expression of which differed between patients with polymyalgia rheumatica (PMR) and non-PMR control subjects before prednisolone treatment and which also responded to treatment with prednisolone in a given direction only in PMR patients. The clusters and the enrichment scores (the geometric means of the EASE scores [24] of all terms in the cluster) were derived using the Database for Annotation, Visualization and Integrated Discovery (DAVID) tool [23]. Green squares denote that the gene/term association has been positively reported; black squares denote that the gene/term association has not yet been reported. a Cluster with an overall theme of regulation of transcription and with an enrichment score of 1.59. $\mathbf{b}$ Cluster with an overall theme of translation/protein biosynthesis and with an enrichment score of 0.63

differentially expressed in symptom-yielding muscle tissue. However, using the more sensitive qRT-PCR technique, the expression of the IL6 gene showed marked differences between groups, being up-regulated in untreated patients and down-regulated after prednisolone treatment (Fig. 5). This finding is in line with a previous microdialysis study that indicated a local production of IL-6 in symptom-yielding muscles in patients with PMR, and normalization with prednisolone treatment [5]. Furthermore, several studies $[1,4,5,25]$ have found that plasma IL-6 is highly elevated in PMR. In line with a key role in the pathophysiology of the disease, IL- 6 blockade has recently in an open-label study been shown to be an effective treatment for newly diagnosed PMR [26].

\section{Genes differentially expressed in untreated PMR patients vs controls}

The applied study design allowed for 3 important comparisons. Firstly, by comparing expressions levels in untreated patients and control subjects, 78 genes of possible central importance for the phenotype of PMR were identified.

Although the enrichment scores, which are proportional to the extent to which the cluster is represented in the gene set (here 78 genes), were modest within this subset of genes, functional clustering analysis identified several clusters of genes, many of which were associated with protein translation and biosynthesis. Other identified clusters included regulation of transcription, cellular and nuclear protein transport, and rearrangement of the cytoskeleton; the latter process was also represented in a gene cluster that involved $\mathrm{SH}$-3-domain-binding properties, which are associated with cytoskeletal elements and signaling proteins.

The identification of clusters associated with protein translation, biosynthesis and transport may suggest that PMR is associated with abnormal protein metabolism in muscle. It might be speculated that inflammation 

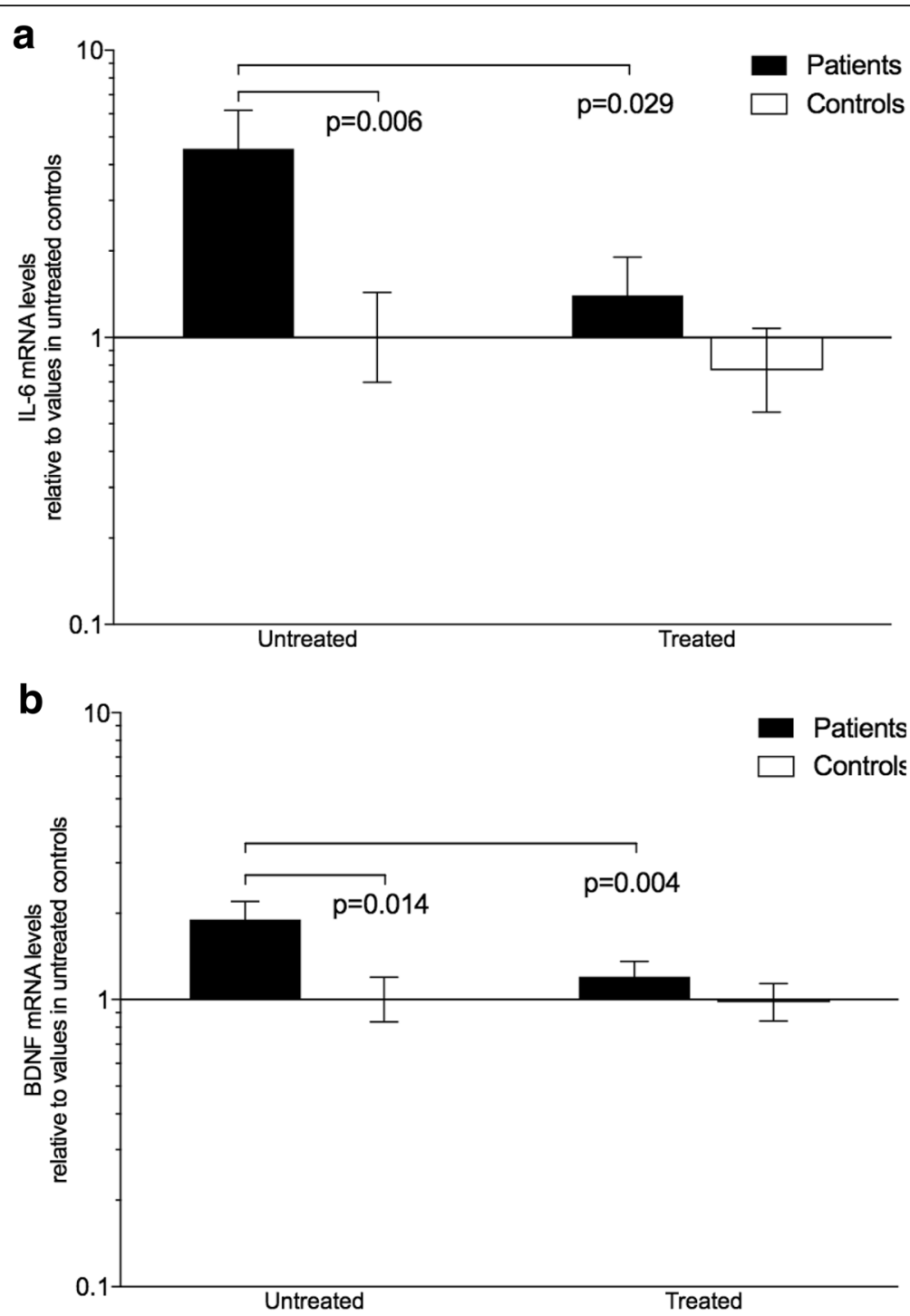

Fig. 5 Muscle (a) interleukin 6 (IL-6) and (b) brain-derived neurotrophic growth factor (BDNF) mRNA levels normalized to the mRNA levels of the gene encoding ribosomal protein, large PO (RPLPO; arbitrary units), in patients with polymyalgia rheumatica (PMR, $n=9$ ) and non-PMR control subjects $(n=9)$ before and after treatment with prednisolone $(20 \mathrm{mg} /$ day) for 14 days. Values are relative to untreated controls $(=1.0)$ and shown on a logarithmic scale. Data are geometric mean and errors bars SEM

and immobilization, which induce negative protein balance in many chronic diseases, accounted for these findings. However, in the protein translation and biosynthesis clusters, more genes were up-regulated rather than down-regulated in patients versus controls in the present cohort. Furthermore, indicating a minor role of inactivity in the present study, the number of genes in muscle influenced by PMR was small compared to findings in response to inactivity per se [27].

Another finding that may possibly contribute to the muscle complaints, primarily the muscle stiffness, experienced by PMR patients [28] is that proteins involved in organizing the cytoskeleton, including tubulin delta 1
(TUBD1; similar findings with microarrays and with qRT-PCR) and microtubule affinity-regulating kinase 4 (MARK4; similar differences in microarray and qRTPCR, but only significant in the former), were upregulated in patients before prednisolone treatment (Tables 2 and 5) [28].

Another interesting gene in this subset was the gene encoding brain-derived neurotrophic growth factor (BDNF). This neurotrophic growth factor was markedly upregulated in patients before treatment as determined by both microarray and qRT-PCR (Tables 2 and 5, Fig. 5). While BDNF traditionally is associated with diseases such as Alzheimer's and mood disorders [29], studies have shown that BDNF is also expressed in satellite cells surrounding 
skeletal muscle cells, and, based on studies in rats, a role for BDNF in maintaining the satellite cell population has been suggested [30]. We have previously shown that PMR is associated with high intramuscular levels of proinflammatory cytokines [5], and it might be speculated that in untreated PMR, BDNF is upregulated to counter the muscle damage resulting from the inflammatory processes as well as the muscle degeneration resulting from the reduced physical activity level of PMR patients.

Finally, the transferrin receptor/CD71 (TFRC) gene was down-regulated 3 fold in patients before treatment. The transferrin receptor protein is involved in the transport of iron into cells, it is required for erythrocyte development, and it is associated with diseases such as iron deficiency, anemia, and chronic disease in general. It has been suggested that low levels of soluble transferrin receptors reflect adaptation to iron deficiency and/or inhibition of iron resorption [31]. It is conceivable that in this group of patients, TFRC is down-regulated due to the chronic inflammatory disease burden associated with PMR. While intramyocellular iron deficiency may ensue, it is not likely that the muscular down regulation of TFRC was secondary to systemic iron deficiency. This is so because none of the subjects exhibited anemia. Other studies have identified that PMR is associated with antibodies against ferritin [32, 33]. Taken together, this suggests that iron metabolism and the function of proteins that rely on iron-binding may be influenced in PMR.

\section{Genes responding to prednisolone in PMR patients}

The phenotype of PMR in this and other studies $[1,5$, $15,34]$ profoundly responds to treatment with glucocorticoids, indicating that important information about the pathophysiology of the disease can be achieved by studying the gene expression before and after prednisolone treatment. Moreover, if studying only untreated subjects, it is conceivable that, due to sampling errors, including unrecognized impacts of e.g. diurnal gene expression variations between patients and controls, discovery of all genes relevant to the pathophysiology of PMR would not be achieved. For these reasons, comparison of expression levels before and after symptom eliminating prednisolone treatment in patients was also used for the identification of genes with importance for PMR. The number of genes that responded to treatment in a given direction only in patients was 131. Indicating that these genes were, in fact, involved in the pathophysiology of PMR, of the 131 mentioned genes that responded to treatment in patients, only 2 also responded in controls subjects, and they did so in the direction opposite to that seen in the patients. Genes responding in the same direction to prednisolone in both patients and controls were not emphasized, because it is likely that the response reflected a general effect of glucocorticoids of no importance for the pathophysiology of PMR.

The functional clusters in this subset of genes included genes involved in the organization of the cytoskeleton and genes relevant for the extracellular matrix. In this context, it is of note that both TUBD1 and MARK4 were down-regulated by prednisolone, the fold changes being significant in microarray and qRT-PCR, respectively (Table 5). The fact that such genes respond to prednisolone treatment in patients with PMR is in line with the hypothesis that muscle stiffness may be due to abnormal expression of cytoskeleton-related genes. Correspondingly, clinical remission, including abolishment of muscle stiffness, happened in parallel with or due to normalization of expression of such genes.

\section{Genes differentially expressed in untreated PMR patients vs controls and also responding to prednisolone in patients}

The strongest evidence in favor of a pathogenic role of a given gene would be that its expression differed between untreated patients and controls, and, furthermore, changed with prednisolone treatment in the former. The number of such genes was 44 in the present cohort. Strongly indicating that these genes do in fact play a role in PMR, the response to prednisolone of all but one of the 44 genes counteracted the difference in gene expression between untreated patients and controls. In this group of genes, the predominant biological functions appeared to be regulation of transcription as well as protein translation/biosynthesis.

The finding that the expression of some genes differed between untreated patients and controls while not responding to prednisolone treatment in patients may indicate that clinical remission may be achieved even though the underlying disease mechanisms are not completely resolved or that not all differences in gene expression may be of importance for clinical symptoms. As a limitation of the present study, it should be noted, however, that while all patients achieved clinical remission during the relatively brief 14-day treatment period, some genes might respond to long-term treatment only. Conversely, it is also interesting to note that in the untreated patients, some genes, the expression of which did not differ from that of controls, were, nevertheless, selectively influenced by prednisolone. It may be that in the patients the processes regulated by these genes were impaired by other, non-genetic factors that possibly also resulted in increased sensitivity to prednisolone. If so, the condition would be ameliorated by a prednisoloneinduced effect on these genes. 


\section{Conclusions}

This study is the first to demonstrate changes in the gene expression in skeletal muscle in PMR. The study has identified a number of genes that may play a role in the pathophysiology of PMR. Moreover, we show that the expression of the IL6 gene is upregulated in muscle in PMR, a finding that adds to the substantial body of evidence that this cytokine is central to the disease. Follow-up studies are needed to elucidate the exact pathophysiological relevance of the identified genes; however, it appears that many of the genes are involved in the regulation of protein biosynthesis, which may suggest that abnormal protein metabolism is a disease mechanism in PMR. Effects of prednisolone on genes involved in the organization of the cytoskeleton and the intracellular matrix in PMR patients may contribute to the amelioration, seen in response to treatment, of the muscle stiffness.

\section{Abbreviations}

CRP: C-reactive protein; ESR: Erythrocyte sedimentation rate;

GC: Glucocorticoid; IL: Interleukin; PMR: Polymyalgia rheumatica; qRT-

PCR: Quantitative real-time polymerase chain reaction

\section{Acknowledgements}

Lisbeth Kall is thanked for skilled technical assistance.

\section{Availability of data and material}

The microarray data were submitted to the gene expression repository at Array Express (http://www.ebi.ac.uk/arrayexpress/) with accession number E-MTAB-3671.

\section{Funding}

The study was supported by grants from the Danish Rheumatism Association (grant number 233-463-14.10.05), Nordea foundation (healthy aging grant) and by the Danish Medical Research Council (grant number 271-06-0311).

\section{Authors' contributions}

HG conceived of the study and, together with FFK, planned its design, recruited and examined the subjects and carried out the experiments. RB, FCN, FFK and PS carried out the biochemical analyses, while all authors participated in the analysis of the data and the writing of the manuscript.

\section{Ethics approval and consent to participate}

The study was approved by the Ethical Committee of Copenhagen (approval number: KF[01]261665) and informed consent was obtained before study inclusion.

\section{Consent for publication}

All subjects gave their consent to publication of obtained data.

\section{Competing interests}

The authors declare that they have no financial or nonfinancial competing interests.

\section{Publisher's Note}

Springer Nature remains neutral with regard to jurisdictional claims in published maps and institutional affiliations.

\section{Author details}

${ }^{1}$ Institute for Inflammation Research, Department of Rheumatology Rigshospitalet, Copenhagen University Hospital, Copenhagen, Denmark. ${ }^{2}$ Center for Genomic Medicine Rigshospitalet, Copenhagen University Hospital, Copenhagen, Denmark. ${ }^{3}$ Institute of Sports Medicine, Department of Orthopedic Surgery M Bispebjerg Hospital and Center for Healthy Aging
Faculty of Health and Medical Sciences, University of Copenhagen, Copenhagen, Denmark.

Received: 13 December 2016 Accepted: 31 July 2017

Published online: 07 August 2017

\section{References}

1. Salvarani C, Cantini F, Boiardi L, Hunder GG. Polymyalgia rheumatica and giant-cell arteritis. N Engl J Med. 2002;347:261-71. doi:10.1056/ NEJMra011913.

2. Nesher G. Polymyalgia rheumatica - diagnosis and classification. J Aotoimmun. 2014:48-49:76-8.

3. Kermani TA, Warrington KJ. Polymyalgia rheumatica. Lancet. 2013;381:63-72.

4. Martinez-Taboada VM, Alvarez L, RuizSoto M, Marin-Vidalled MJ, LopezHoyos M. Giant cell arteritis and polymyalgia rheumatica: role of cytokines in the pathogenesis and implications for treatment. Cytokine. 2008;44:20720. doi:10.1016/j.cyto.2008.09.004.

5. Kreiner $F$, Langberg $H$, Galbo $H$. Increased muscle interstitial levels of inflammatory cytokines in polymyalgia rheumatica. Arthritis Rheum. 2010;62: 3768-75. doi:10.1002/art.27728.

6. Healey LA. Polymyalgia rheumatica is the result of synovitis. J Clin Rheumatol. 2006:12:165-6. doi:10.1097/01.rhu.0000230445.14861.fa.

7. Dasgupta B, Borg F, Hassan N, Barraclough K, Bourke B, et al. BSR and BHPR guidelines for the management of polymyalgia rheumatica. Rheumatology. 2009; doi:10.1093/rheumatology/kep303a.

8. Dejaco C, Singh YP, Perel P, Hutchings A, Camellino D, Mackie S, et al. 2015 recommendations for the management of polymyalgia rheumatica: $A$ European League Against Rheumatism/American College of Rheumatology collaborative initiative. Arthritis Rheumatol. 2015;67:2569-80.

9. Gabriel S, Sunku J, Salvarani C, O'Fallon W, Hunder GG. Adverse outcomes of antiinflammatory therapy among patients with polymyalgia rheumatica. Arthritis Rheum. 1997:40:1873-8.

10. Gonzalez-Gay M, Vazquez-Rodriguez T, Lopez-Diaz M, Miranda-Filloy J, Gonzalez-Juanatey C, et al. Epidemiology of giant cell arteritis and polymyalgia rheumatica. Arthritis Rheum. 2009:61:1454-61. doi:10.1002/art. 24459.

11. Martínez-Taboda VM, Bartolome MJ, Lopez-Hoyos M, Blanco R, Mata C, et al. HLA-DRB1 allele distribution in polymyalgia rheumatica and giant cell arteritis: influence on clinical subgroups and prognosis. Semin Arthritis Rheum. 2004;34:454-64

12. González-Gay MA, Amoli MM, Garcia-Porrua C, Ollier WER. Genetic markers of disease susceptibility and severity in giant cell arteritis and polymyalgia rheumatica. Semin Arthritis Rheum. 2003;33:38-48. doi:10.1053/sarh.2002. 50025 .

13. Salvarani C, Casali B, Farnetti E, Pipitone N, Nicoli D, et al. Interleukin-6 promoter polymorphism at position -174 in giant cell arteritis. J Rheumatol. 2005;32:2173-7

14. Boiardi L, Casali B, Farnetti E, Pipitone N, Nicoli D, et al. Relationship between interleukin 6 promoter polymorphism at position -174, IL-6 serum levels, and the risk of relapse/recurrence in polymyalgia rheumatica. J Rheumatol. 2006;33:703-8.

15. Kreiner $F$, Galbo H. Elevated muscle interstitial levels of pain-inducing substances in symptomatic muscles in patients with polymyalgia rheumatica. Pain. 2011;152:1127-32. doi:10.1016/j.pain.2011.01.032

16. Chuang TY, Hunder GG, Ilstrup DM, Kurland LT. Polymyalgia rheumatica: a 10-year epidemiologic and clinical study. Ann Intern Med. 1982;97:672-80.

17. Dasgupta B, Cimmino MA, Maradit-Kremers H, Schmidt WA, Schirmer M, Salvarani C, et al. 2012 provisional classification criteria for polymyalgia rheumatica: a European League Against Rheumatism/American College of Rheumatology collaborative initiative. Ann Rheum Dis. 2012;71:484-92.

18. Bergstrom J. Percutaneous needle biopsy of skeletal muscle in physiological and clinical research. Scand J Clin Lab Invest. 1975;35:609-16.

19. Borup R, Rossing M, Henao R, Yamamoto Y, Krogdahl A, et al. Molecular signatures of thyroid follicular neoplasia. Endocr Relat Cancer. 2010;17: 691-708. doi:10.1677/ERC-09-0288.

20. Gentleman RC, Carey VJ, Bates DM, Bolstad B, Dettling M, et al. Bioconductor: open software development for computational biology and bioinformatics. Genome Biol. 2004;5:R80. doi:10.1186/gb-2004-5-10-r80.

21. Bolstad BM, Irizarry RA, Astrand M. Speed TP A comparison of normalization methods for high density oligonucleotide array data based on variance and bias. Bioinformatics. 2003;19:185-93. 
22. Benjamini Y, Drai D, Elmer G, Kafkafi N, Golani I. Controlling the false discovery rate in behavior genetics research. Behav Brain Res. 2001;125: 279-84.

23. Huang DW, Sherman BT, Lempicki RA. Systematic and integrative analysis of large gene lists using DAVID bioinformatics resources. Nat Protoc. 2009;4: 44-57. doi:10.1038/nprot.2008.211.

24. Hosack DA, Dennis G, Sherman BT, Lane HC, Lempicki RA. Identifying biological themes within lists of genes with EASE. Genome Biol. 2003;4:R70. doi:10.1186/gb-2003-4-10-r70

25. Kreiner F, Galbo H. Effect of etanercept in polymyalgia rheumatica: a randomized controlled trial. Arthritis Res Thera. 2010;12:R176. doi:10.1186/ ar3140.

26. Lindsay L, Forbess L, Hatzis C, Spiera R. A prospective open-label phase lla trial of Tocilizumab in the treatment of polymyalgia rheumatica. Arthritis \& Rheumatology. 2016:68:2550-4.

27. Timmons JA, Norrbom J, Schéele C, Thonberg H, Wahlestedt C, et al. Expression profiling following local muscle inactivity in humans provides new perspective on diabetes-related genes. Genomics. 2006;87:165-72. doi:10.1016/j.ygeno.2005.09.007.

28. Kjaer M. Role of extracellular matrix in adaptation of tendon and skeletal muscle to mechanical loading. Physiol Rev. 2004;84:649-98. doi:10.1152/ physrev.00031.2003.

29. Zuccato C, Cattaneo E. Brain-derived neurotrophic factor in neurodegenerative diseases. Nat Rev Neurol. 2009;5:311-22. doi:10.1038/ nrneurol.2009.54.

30. Mousavi K, Jasmin BJ. BDNF is expressed in skeletal muscle satellite cells and inhibits myogenic differentiation. J Neurosci. 2006;26:5739-49. doi:10.1523/JNEUROSCI.5398-05.2006.

31. Aisen P. Transferrin receptor 1. Int J Biochem Cell Biol. 2004;36:2137-43. doi:10.1016/j.biocel.2004.02.007.

32. Baerlecken NT, Linnemann A, Gross WL, Moosig F, Vazquez-Rodriguez TR, et al. Association of ferritin autoantibodies with giant cell arteritis/polymyalgia rheumatica. Ann Rheum Dis. 2012;71:943-7. doi:10.1136/annrheumdis-2011200413

33. Große K, Schmidt R, Witte T, Baerlecken N. Epitope mapping of antibodies against ferritin heavy chain in giant cell arteritis and polymyalgia rheumatica. Scand J Rheumatol. 2013:42:215-9. doi:10.3109/03009742.2012. 733959.

34. Kreiner F, Galbo H. Insulin sensitivity and related cytokines, chemokines, and adipokines in polymyalgia rheumatica. Scand J Rheumatol. 2010;39:402-8. doi:10.3109/03009741003631479.

\section{Submit your next manuscript to BioMed Central and we will help you at every step:}

- We accept pre-submission inquiries

- Our selector tool helps you to find the most relevant journal

- We provide round the clock customer support

- Convenient online submission

- Thorough peer review

- Inclusion in PubMed and all major indexing services

- Maximum visibility for your research

Submit your manuscript at www.biomedcentral.com/submit

) Biomed Central 